\title{
Effects of Voluntary Locomotion and Calcitonin Gene-Related Peptide on the Dynamics of Single Dural Vessels in Awake Mice
}

\author{
나 Yu-Rong Gao ${ }^{1,2}$ and $\odot$ Patrick J. Drew ${ }^{1,2,3,4}$ \\ ${ }^{1}$ Center for Neural Engineering, Department of Engineering Science and Mechanics, ${ }^{2}$ Neuroscience Graduate Program, Huck Institutes of the Life Sciences \\ and Departments of ${ }^{3}$ Neurosurgery and ${ }^{4}$ Biomedical Engineering, Pennsylvania State University, University Park, Pennsylvania 16802
}

The dura mater is a vascularized membrane surrounding the brain and is heavily innervated by sensory nerves. Our knowledge of the dural vasculature has been limited to pathological conditions, such as headaches, but little is known about the dural blood flow regulation during behavior. To better understand the dynamics of dural vessels during behavior, we used two-photon laser scanning microscopy (2PLSM) to measure the diameter changes of single dural and pial vessels in the awake mouse during voluntary locomotion. Surprisingly, we found that voluntary locomotion drove the constriction of dural vessels, and the dynamics of these constrictions could be captured with a linear convolution model. Dural vessel constrictions did not mirror the large increases in intracranial pressure (ICP) during locomotion, indicating that dural vessel constriction was not caused passively by compression. To study how behaviorally driven dynamics of dural vessels might be altered in pathological states, we injected the vasodilator calcitonin gene-related peptide (CGRP), which induces headache in humans. CGRP dilated dural, but not pial, vessels and significantly reduced spontaneous locomotion but did not block locomotion-induced constrictions in dural vessels. Sumatriptan, a drug commonly used to treat headaches, blocked the vascular and behavioral the effects of CGRP. These findings suggest that, in the awake animal, the diameters of dural vessels are regulated dynamically during behavior and during drug-induced pathological states.

Key words: CGRP; dural vessel; locomotion; pial vessel; sumatriptan; two-photon microscopy

\section{Significant Statement}

The vasculature of the dura has been implicated in the pathophysiology of headaches, but how individual dural vessels respond during behavior, both under normal conditions and after treatment with the headache-inducing peptide calcitonin gene-related peptide (CGRP), is poorly understood. To address these issues, we imaged individual dural vessels in awake mice and found that dural vessels constricted during voluntary locomotion, and this constriction did not follow locomotion-induced intracranial pressure increases. CGRP injection caused baseline dural vessel dilation and reduced locomotion but did not block locomotioninduced constrictions of dural vessels or affect pial vessels. These novel findings reveal dynamic regulation of dural vessels that are distinct from those in cerebral blood vessels during both normal behavior and after dilation by CGRP.

\section{Introduction}

Cerebral arterioles form an interconnected network on the pial surface that transports blood to the cortex (Tsai et al., 2009; Blinder et

Received Sept. 21, 2015; revised Jan. 15, 2016; accepted Jan. 21, 2016.

Author contributions: Y.-R.G. and P.J.D. designed research; Y.-R.G. performed research; Y.-R.G. analyzed data; Y.-R.G. and P.J.D. wrote the paper.

This work was supported by National Scientist Development Grant 12SDG9130022 from the American Heart Association, a Scholar Award from the McKnight Endowment Fund for Neuroscience, National Institutes of Health Grants NS078168 and NS079737 (P.J.D.), the Huck Institute Graduate Enrichment Fund (Y.-R.G.), and American Recovery and Reinvestment Act stimulus funds through Grant NS070701. We thank P. Albrich for advice on dural dissection and P. Blinder and K. C. Brennan for helpful comments on a previous version of this manuscript.

The authors declare no competing financial interests.

Correspondence should be addressed to Patrick J. Drew, Center for Neural Engineering, Pennsylvania State University, W-317 Millennium Science Complex, University Park, PA 16802. E-mail: pjd17@psu.edu. al., 2010, 2013). The dynamics of these cerebral blood vessels have been studied extensively during passive sensory stimulation (Tian et al., 2010; Drew et al., 2011; Nizar et al., 2013) and voluntary behavior (Gao et al., 2015; Huo et al., 2015a,b) to understand neurovascular coupling (Kim and Ogawa, 2012). Superficial to the pial vessels is the dura mater, a vascularized membrane ensheathing the brain and spinal cord. There are three major arterial supplies to the dura mater: (1) the anterior meningeal artery; (2) the middle meningeal artery; and (3) the posterior meningeal artery (Castelli and Huelke, 1965). They anastomose with each other, giving rise to a rich layer of arteries 
on the periosteal surface of the dura (Fricke et al., 2001). Some arteries penetrate into the inner layer of the dura to form a rich capillary network (Kerber and Newton, 1973). Pial veins drain into the dural venous sinuses along the midline (Balo, 1950). The dura and its associated blood vessels are innervated densely by nociceptive nerves from the trigeminal ganglion (Pietrobon and Moskowitz, 2013), and there has been much speculation about the control of dural blood flow. Some have suggested that dural blood supply is dependent only on humoral mechanisms (Martins et al., 2005). However, electrical stimulation of dural nerves causes a biphasic response in dural vessels, with an initial constriction, followed by a dilation (Williamson et al., 1997a; Li et al., 2009), suggesting that a balance of vasodilatory and vasoconstrictory input sets dural vessel tone. Although dural vessels have been examined extensively during headaches and headache-related stimuli, it is not known whether they actively respond during natural behavior in a similar manner to the cortical vasculature.

Early work by Wolff (1948) suggested that dural vessel dilation is involved in headaches, although recent work has cast doubt on this hypothesis (Brennan and Charles, 2010), as well as the idea that vessel dilations are a causal factor in migraine (Schoonman et al., 2008; Amin et al., 2013b). Intravenous injections of the vasodilatory peptide calcitonin gene-related peptide (CGRP) cause immediate headaches in humans (Petersen et al., 2005; Asghar et al., 2010, 2012). However, most animal studies investigating the vascular effects of CGRP have been carried out under anesthesia, which profoundly affects normal vascular function (Berwick et al., 2002; Drew et al., 2011; Masamoto and Kanno, 2012), in addition to blocking pain and preventing behavioral responses. Human studies usually use non-invasive imaging techniques, which have limited spatial resolution, restricting measurements to the largest arteries. It is possible that the smaller dural vessels have different responses than the larger vessels, as the responses of arteries are size dependent (Lee et al., 2001; Drew et al., 2011; Gao et al., 2015). Lastly, it is not known how any behavioral regulation of dural vessel diameter might interact with the vasodilatory effects of CGRP. All of these reasons motivate the study of dural vascular dynamics during CGRP-induced headache state in the awake animal.

To better understand how dural vessels respond during natural behavior under normal conditions and after treatment with CGRP, we imaged dural vessels using two-photon laser scanning microscopy (2PLSM; Shih et al., 2012) in awake mice. Surprisingly, we found that voluntary locomotion significantly constricted dural vessels, and this constriction could not be attributed to passive compression from increased intracranial pressure (ICP). CGRP caused dural vessel dilation and decreased spontaneous locomotion but did not block locomotion-induced constrictions. Our results show that dural vessels actively respond during behavior.

\section{Materials and Methods}

Animals. All surgical and experimental procedures were performed in accordance with National Institutes of Health guidelines and approved by the Pennsylvania State University Institutional Animal Care and Use Committee. A total of 40 C57BL/6 mice (The Jackson Laboratory), aged 2-6 months, were used. Twenty-eight (18 males) were used in 2PLSM imaging experiments, of which 11 (eight males) were used for pharmacology experiments. A separate set of eight mice (five males) were used for ICP measurements. Another four mice (two males) were used for histology. Sample sizes were based on previous studies quantifying pial vessel dynamics (Drew et al., 2011; Huo et al., 2015a). No animals were excluded from analyses.

Surgical and habituation procedures. For 2PLSM measurements, polished and reinforced thinned-skull (PoRTS) windows were implanted over the right somatosensory or visual cortex (Drew et al., 2010; Gao et al., 2015). Mice were anesthetized with isoflurane (5\% for induction, $1.5-2 \%$ for maintenance). A custom-made titanium head bolt was affixed to the skull, and three self-tapping $\# 0003 / 32$ inch screws (JI Morris) were inserted into the skull and attached to the head bolt and skull via dental cement. The window area was first thinned to $\sim 30 \mu \mathrm{m}$ using a 0.7 $\mathrm{mm}$ drill bit (Fine Science Tools) and then polished with $3 \mathrm{~F}$ and $4 \mathrm{~F}$ grit (Convington Engineering). A \#0 coverslip was attached to the polished window area with cyanoacrylate, and the edges were sealed with dental cement. Windows in the somatosensory cortex were centered 1-2 mm caudal and $0-2.5 \mathrm{~mm}$ lateral to bregma. Visual cortex windows were centered 2-4 mm caudal, 1-3 mm lateral to bregma (Franklin and Paxinos, 1997). Mice were allowed to recover for at least $2 \mathrm{~d}$ after the surgery before they were habituated on the imaging setup. Mice were imaged on a spherical treadmill (diameter, $60 \mathrm{~mm}$ ) with a rotation encoder to monitor motion (Huo et al., 2014, 2015a). To minimize stress during imaging, mice were habituated in $15 \mathrm{~min}$ sessions, up to four times a day, for 2-3 d before imaging. Mice were only imaged every other day. Each mouse was imaged repeatedly between 1 week and 1 month after window implantation. Previous studies from our laboratory using head-fixed mice on the same spherical treadmill setup (Huo et al., 2015b) have shown that the heart rate of head-fixed mice are comparable with the heart rate when they are in home cages (Gehrmann et al., 2000), indicating that the stress associated with head fixation is not large enough to affect heart rate. Long-term studies of the dynamic responses of pial vessels to locomotion have shown that the cortical hemodynamic response to locomotion stays stable for months (Huo et al., 2015a), indicating that the animal is comfortable on the setup. Last, many groups have used head-fixed mice to perform complex memory and discrimination tasks (Dombeck et al., 2010; Komiyama et al., 2010; O'Connor et al., 2010; Chen et al., 2012; Sofroniew et al., 2014), in which the mice would not be able to perform if they were stressed by head fixation.

For ICP measurements, a head bolt and screws were implanted as above, and a hole $\sim 0.5 \mathrm{~mm}$ in diameter was drilled in the skull above the left parietal lobe. A pressure sensor (model SPR1000; diameter, $0.33 \mathrm{~mm}$; Millar) was inserted through the hole perpendicularly into the cortex to a depth of $\sim 1 \mathrm{~mm}$. The probe was sealed in place with Kwik-Sil (World Precision Instruments). The intraparechymally measured ICP tracks the epidural ICP very closely (Wiig and Reed, 1983; Hiploylee and Colbourne, 2014). Placing the probe perpendicularly into the brain, rather than between the skull and pia, reduced damage to the pial vascular network that supplies the cortex (Blinder et al., 2013). Control experiments, in which the ICP probe was vibrated in water, showed that rapid motion did not cause detectable pressure changes, and an ICP probe implanted in a dead mouse did not register any ICP changes when the ball was rotated. The mice used in ICP measurement experiments were head fixed on the same treadmill setup as used in the imaging experiments.

Two-photon microscopy. Mice were imaged using a two-photon microscope composed of a Movable Objective Microscope (Sutter Instruments) and a MaiTai HP laser (Spectra-Physics). A 10×, 0.3 numerical aperture (NA; Olympus), a $20 \times, 1.0 \mathrm{NA}$ (Olympus), or a $40 \times, 0.8 \mathrm{NA}$ (Olympus) water-dipping objective were used for imaging. Before each imaging session, animals were anesthetized briefly with isoflurane and were retro-orbitally injected with $50 \mu \mathrm{l}(50 \mathrm{mg} / \mathrm{mL})$ fluoresceinconjugated dextran (FITC; $70 \mathrm{kDa}$; Sigma). For isoflurane vasodilation experiments, mice were placed on a homeothermic heating pad while the animal was anesthetized with $2 \%$ isoflurane in air. Imaging sessions typically lasted $\sim 2 \mathrm{~h}$. Each vessel was imaged for $\sim 5 \mathrm{~min}$ at $\sim 8$ frames/s. Pial arteries and veins were identified based on morphology and dynamics (Blinder et al., 2010; Drew et al., 2011; Huo et al., 2015a). Dural vessels were clearly identifiable as vessels above pial vessels that were unconnected to the pial vascular network (Fig. $1 B$ ), characterized by long, straight, thin vessels with few branches (Fig. $2 A$ ). Dural vessels were selected for imaging based on their diameter, and only noncapillary dural vessels ( $>6 \mu \mathrm{m}$ diameter) were chosen for imaging. Otherwise, no explicit criterion was used to select dural vessels, and they were imaged from all locations within the windows over the somatosensory and visual cortices.

Drug injections. Before drug injection, a dural vessel and nearby pial arteries or veins were imaged for $\sim 10$ min to obtain baseline diameter 

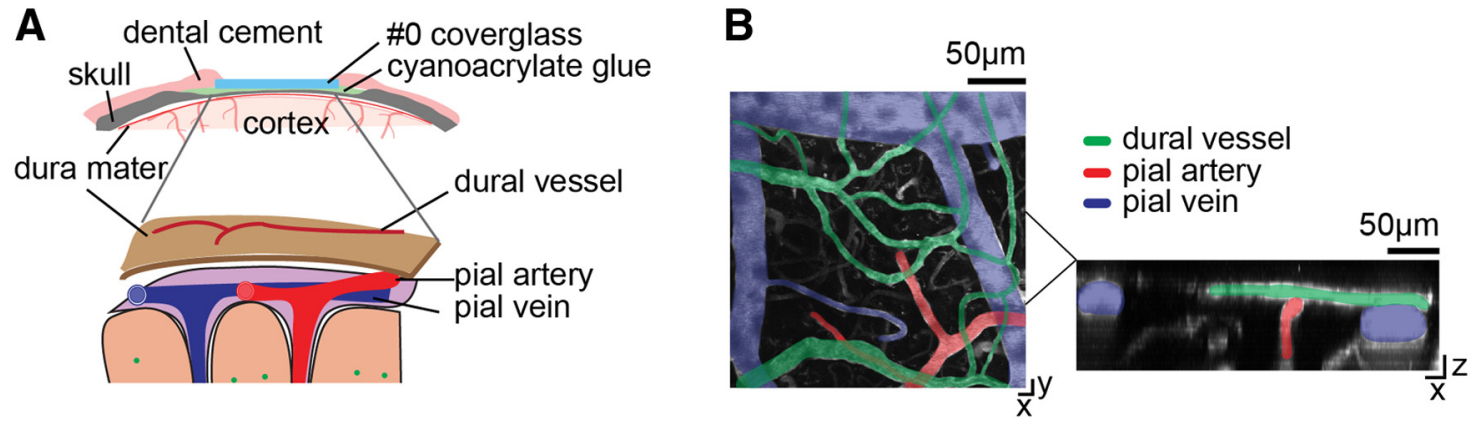

Figure 1. Dural and pial vessels form separate vascular networks and can be imaged concurrently through the PoRTS window. $A$, Top, Schematic of the PoRTS window. Bottom, Schematic of dural and cortical vascular systems. The separation of dural and pial vessels has been exaggerated for clarity. $\boldsymbol{B}$, Left, $z$ projection of a 2PLSM image of surface vasculatures. Green, dural vessels; red, pial arteries; blue, pial veins. Right, $x-z$ view of the $y$ projection of the denoted subregion.

measurements. The mouse was then briefly $(<1 \mathrm{~min})$ anesthetized with isoflurane while the drug or drugs were injected retro-orbitally. Drugs were administered in a separate injection from the FITC injection. Injections were $50 \mu \mathrm{l}$ in volume and contained $10^{-3} \mathrm{mg} / \mathrm{kg}$ rat CGRP (Sigma) in saline, $0.3 \mathrm{mg} / \mathrm{kg}$ sumatriptan (Sigma) in saline, both CGRP and sumatriptan, or saline alone. The CGRP and sumatriptan doses were chosen to be comparable with the human doses that induce and prevent headaches, respectively (Lassen et al., 2002; Asghar et al., 2010). Imaging resumed $5 \mathrm{~min}$ after injection to allow the vasculature to recover from the effects of isoflurane (Shirey et al., 2015). The vessels were then imaged for $45 \mathrm{~min}$ after the drug injections to monitor any vascular changes. Animals were given at least $2 \mathrm{~d}$ of recovery between drug injections. The order of drug injection was randomized, and each drug was injected at least once in each animal, up to three times (average number of injections per animal, $1.4 \pm 0.6$ ). The experimenter was not blinded to the drug injected but was blinded during the analysis.

ICP measurements. Before each experiment, the pressure sensor was calibrated. ICP and treadmill velocity recordings started after the animal recovered from anesthesia, continuing for 0.5 to $1.5 \mathrm{~h}$ after surgery. The pressure sensor was connected to the PCU-2000 pressure control unit (Millar). ICP and ball velocity were digitized at $2 \mathrm{kHz}$ (NI USB-6343; National Instruments) and then down sampled to $20 \mathrm{~Hz}$. The ICP data were filtered with a five-point median filter and low-pass filtered at $3 \mathrm{~Hz}$ (third-order Butterworth). The average ICP was calculated $0-5$ min before isoflurane administration, nominally $4 \mathrm{~min}$ under isoflurane, and 5-15 min after isoflurane. At the conclusion of the ICP experiment, the animal was killed.

Image processing and data analysis. Data analysis was performed in MATLAB (MathWorks). Statistical tests were performed in SAS (version 9.3; SAS Institute). 2PLSM images were aligned in the $x-y$ plane using a rigid registration algorithm (Drew et al., 2011; Gao et al., 2015; Huo et al., 2015a). Visual inspection of movies indicated that $z$-axis motion during locomotion was minimal (Fig. $3 A, C$ ). A rectangular box was drawn manually around a short segment (typically $2-5 \mu \mathrm{m}$ in length) of a vessel. Pixel intensity was averaged along the long axis of the vessel, and the diameter was calculated from the full-width at half-maximum (Drew et al., 2011; Gao et al., 2015; Huo et al., 2015a). Frames in which the temporal derivative of diameter changed by $>16 \mu \mathrm{m} / \mathrm{s}$ were tagged as motion artifacts and were removed. Removed frames were replaced with the linear interpolation between the proceeding and subsequent points. Fractional changes in vessel diameter $\left(\Delta D / D_{0}\right)$ were calculated by normalizing to the average diameter during a manually chosen $\sim 10$-s-long stationary period (Gao et al., 2015; Huo et al., 2015a). The $\Delta D / D_{0}$ time series was first filtered with a five-point median filter and then low-pass filtered at $3 \mathrm{~Hz}$ (third-order Butterworth). To detect locomotion events, the velocity signal was low-pass filtered $(10 \mathrm{~Hz}$, fifthorder Butterworth), and then the absolute value of the acceleration was binarized with a $10^{-5} \mathrm{~cm} / \mathrm{s}^{2}$ threshold (Huo et al., 2014, 2015a).

To compare the effects of different pharmacological agents on diameter, the ratio of the averaged vessel diameter during stationary periods after drug injection to the resting baseline diameter before drug injection was taken. Stationary periods were defined as times when the mouse was still, with a $2 \mathrm{~s}$ buffer after the cessation of locomotion and a $1 \mathrm{~s}$ buffer before the start of subsequent locomotion events. We waited $5 \mathrm{~min}$ after the injection to ensure that the vasodilatory effects of isoflurane had passed (Shirey et al., 2015). For statistical analysis, two-way ANOVA (unbalanced general linear model procedure, four levels of drug, three levels of vessel type) was used to compare vessel diameter ratios after different drug treatments. A one-way ANOVA (unbalanced general linear model procedure, four levels of drug) was used to compare locomotion ratios after different drug treatments. The fraction of time spent locomoting was logarithmically transformed to normalize the data.

To quantitatively describe the changes in vessel diameters associated with locomotion, vessel diameter changes were fitted with a linear convolution model (Huo et al., 2015a). The input was the binarized locomotion signal, whereas the output was the changes in vessel diameter, $\Delta D /$ $D_{0}: \Delta D / D_{0}=\vec{s} * \vec{g}+C$, where $*$ denotes the convolution operation, $\vec{s}$ was the vector of binary locomotion events and $\vec{g}$ was the hemodynamic response function (HRF; Boynton et al., 1996; Vazquez and Noll, 1998; Silva et al., 2007), and $C$ was a constant offset. The HRF was fitted with the following function:

$$
\vec{g}=\left\{\begin{array}{c}
0, t \leq t_{d} \\
A \times e^{-\left(t-t_{d}\right) / \tau}, \quad t>t_{d}
\end{array} .\right.
$$

This function had three free parameters to be fitted: (1) amplitude $A$; (2) time constant $\tau$; and (3) response onset delay $t_{d}$. All parameters were fit by minimizing the mean-square error between the experimental measurements and estimate of the convolution model using the MATLAB function fminsearchbnd, using empirically determined bounds on the fit algorithm. For dural vessels the bounds were $-20 \leq A \leq 20,0.5 \mathrm{~s} \leq \tau \leq$ $150 \mathrm{~s}$, and $-20 \mathrm{~s} \leq t_{d} \leq 20 \mathrm{~s}$. For pial arteries and veins, we used $-20 \leq$ $A \leq 120,0.5 \mathrm{~s} \leq \tau \leq 150 \mathrm{~s}$, and $-20 \mathrm{~s} \leq t_{d} \leq 20 \mathrm{~s}$. ICP changes were quantified with a linear convolution model with an exponential kernel with the parameter boundaries: $-20 \leq A \leq 20,0 \mathrm{~s} \leq \tau \leq 100 \mathrm{~s}$, and $-20 \mathrm{~s} \leq t_{d} \leq 20 \mathrm{~s}$.

Histology. To anatomically identify arteries and veins in the dura and brain, animals were perfused transcardially with heparin-saline and $4 \%$ paraformaldehyde (PFA) and then flushed with 1\% FITC-albumin and $2 \%$ gelatin in PBS, after which the animals were placed head down in ice for $15 \mathrm{~min}$ (Tsai et al., 2009). A complete vascular fill was characterized by the complete filling of the sagittal sinus with FITC-albumin. The head was fixed in $4 \%$ PFA for $2 \mathrm{~d}$, and the brain was exposed from the base by cutting the jaw and lifted up to leave the dura on the skull. The dura was then dissected carefully from the skull (Rice et al., 2015). The whole brains and dura were washed in $0.1 \mathrm{M}$ PBS for $15 \mathrm{~min}$ three times and incubated in $1 \%$ Triton X-100 in $0.1 \mathrm{~m}$ PBS for $1 \mathrm{~h}$, and the samples were then stained with 1:250 diluted rhodamine-conjugated phalloidin (Life Technologies) in PBS at $4^{\circ} \mathrm{C}$ for $72 \mathrm{~h}$ (Gao et al., 2015). The brain and dura were rinsed for $30 \mathrm{~min}$ in PBS three times before being imaged using 2PLSM. 
A

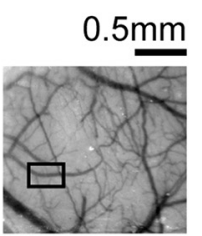

B
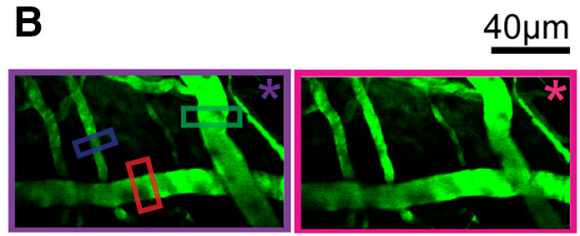

C

-Dural vessel - Vein । Locomotion $1 \%$ dural,artery -Artery - Fitted response $3 \%$ vein<smiles>C1CCCCC1</smiles>
I I


D

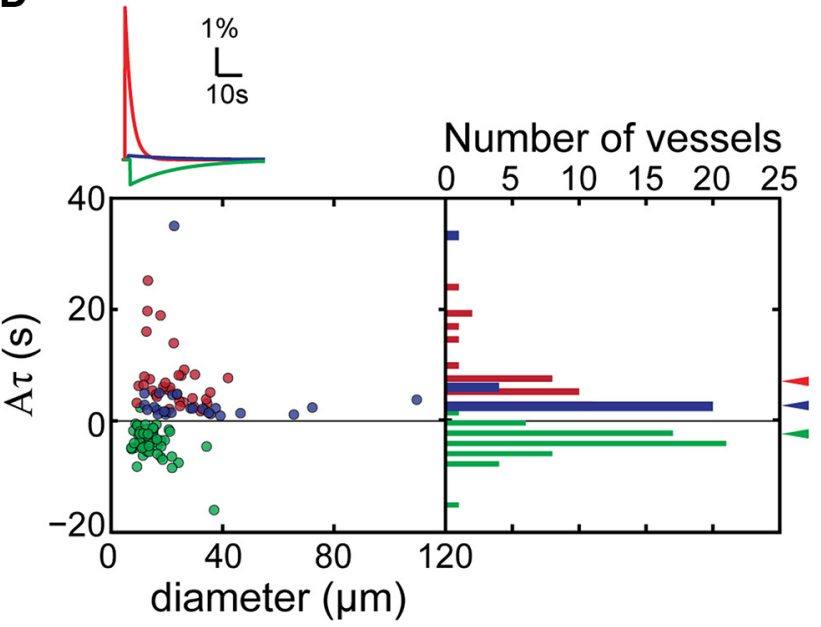

Figure 2. Dural vessels in the somatosensory cortex constricted during voluntary locomotion. $\boldsymbol{A}$, Photo of the cerebral and dural vasculature of the somatosensory cortex through a PoRTS window. The black box encloses the area imaged by 2PLSM that contains the vessels in $\boldsymbol{B}$. $\boldsymbol{B}$, Maximum projection of $2 \mathrm{PLSM}$ images of measured vasculature during periods of quiescence (left, enclosed by purple box, $48 \mathrm{sin}$ C) and locomotion (right, enclosed by magenta box, $168 \mathrm{~s}$ in $\boldsymbol{C}$. Green, red, and blue boxes enclose the measured dural vessel, pial artery, and pial vein, respectively. $\boldsymbol{C}$, Time courses of diameter changes of the three vessels in $\boldsymbol{B}$ (top, dural vessel; middle, pial artery; bottom, pial vein). Black tick marks on the top denote locomotion events. Purple and magenta asterisks indicate the time points of quiescence and locomotion images in $\boldsymbol{B}$. Gray lines show the best fit with the linear convolution model of each of the three vessels (correlation coefficient between data and fit for dural vessel, $c c=0.76$; artery, $c c=0.82$; vein, $c c=0.64)$. Insets are the fitted impulse responses of the respective vessel. $D$, Summary of the values of fitted impulse response integrated area $(A \tau)$ of all the imaged vessels in the somatosensory cortex ( $n=21$ mice). Gray line indicates zero. Green, red, and blue arrowheads indicate the mean $A \tau$ of dural vessels, pial arteries, and pial veins, respectively. With one locomotion impulse, the integrated dilation in arteries $(6.9 \pm 5.4 \mathrm{~s})$ was larger than that in veins (3.67 \pm $6.65 \mathrm{~s}, p=0.04$, paired $t$ test), whereas the integrated dural vessel dilation was negative $\left(-3.80 \pm 2.64\right.$, significantly smaller than $0, p=6.26 \times 10^{-16}$, one-sided $t$ test). The inset shows the average impulse response of each vessel type.

\section{Results}

We used 2PLSM (Drew et al., 2011) to visualize diameter changes of dural and pial vessels (Fig. $1 A$ ) in awake mice on a spherical treadmill during voluntary locomotion (Gao and Drew, 2014; Huo et al., 2014, 2015a; Gao et al., 2015) and in response to intravenous injections of CGRP and/or sumatriptan. Although both dural vessels and pial veins drain into the sagittal sinus (Castelli and Huelke, 1965; Kerber and Newton, 1973; Fricke et al., 2001), our windows were more laterally located, such that dural vessels were clearly distinguishable from pial vessels by their superficial position relative to cerebral arteries and veins (Fig. 1) and the lack of interconnections between the dural vasculature and cortical blood vessels. The average resting diameter of the measured dural vessels was $17.5 \pm 9.2 \mu \mathrm{m}$, pial arteries was $20.5 \pm 8.5 \mu \mathrm{m}$, and pial veins was $32.5 \pm 20.4 \mu \mathrm{m}$. All reported summary numbers are mean $\pm \mathrm{SD}$, and error bars and shaded areas in plots denote $1 \mathrm{SD}$, unless indicated otherwise.

\section{Voluntary locomotion drove dural vessel constriction in the somatosensory cortex}

We first asked whether dural vessels respond to voluntary locomotion in the same manner as pial vessels. Voluntary locomotion drives large increases in cerebral blood volume (Huo et al., 2014) because of neurogenic/astrocytic dilation of arterioles (Gao et al., 2015; Huo et al., 2015a) and venules. Some, but not all, of the venule dilation is attributable to the increased blood pressure associated with locomotion (Huo et al., 2015b). Dural vessels come into contact with pial vessels and are $<20 \mu \mathrm{m}$ from the pial surface (Fig. 1). They might be dilated by the spillover of vasodilators, such as nitric oxide, which can easily diffuse the distance from the upper layers of cortex to the dural vessels (Wood and Garthwaite, 1994; Du et al., 2015). Alternatively, dural vessels might be compressed passively by the increase in ICP that accompanies large increases in cerebral blood volume. Another possibility is that dural vessels could be actively controlled during behavior by peripheral nerve innervation.

Surprisingly, we observed that voluntary locomotion was accompanied by the constriction of dural vessels in the somatosensory cortex (Fig. 2), whereas nearby pial arteries and veins were observed to dilate during locomotion. Because locomotion patterns in mice are temporally variable, we used a linear convolution model (Boynton et al., 1996; Hirano et al., 2011; Huo et al., 2015a), which is used extensively to capture the hemodynamic response to stimulation in functional imaging (Boynton et al., 1996; Vazquez and Noll, 1998). Linear convolution models allow us to quantify the dynamics of the response of a vessel to voluntary locomotion, as well as to accurately predict their responses to arbitrary patterns of locomotion (Huo et al., 2015a). With a linear convolution model, the output is the fractional change in vessels diameter, the input is the binarized locomotion (Huo et al., 2014, 2015a), and the fitted kernel, or HRF, which quantifies the relationship between the behavior and vessel diameter change, represents the responses of the vessel to a brief locomotion bout. We used exponential kernels because they do a good job of capturing the dynamics of pial vessel responses (Huo et al., 2015a), and the fit parameters have clearly interpretable physiological meanings. The kernel had three parameters ( $A$, amplitude; $\tau$, time constant; $t_{d}$, onset delay). The amplitude parameter $(A)$ determines how large a response and the nature of the response (dilation or constriction) of the vessel to a single locomotion event. The time constant $(\tau)$ determines how fast the vessel relaxes back to baseline after locomotion ceased, and the delay parameter $\left(t_{d}\right)$ is the difference between the start of the diameter 
A
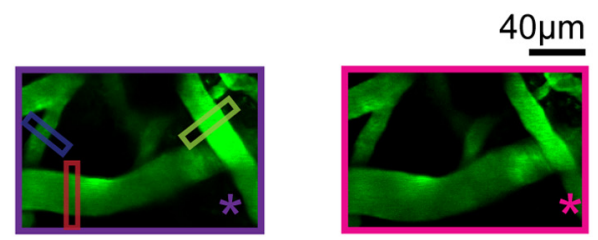

B
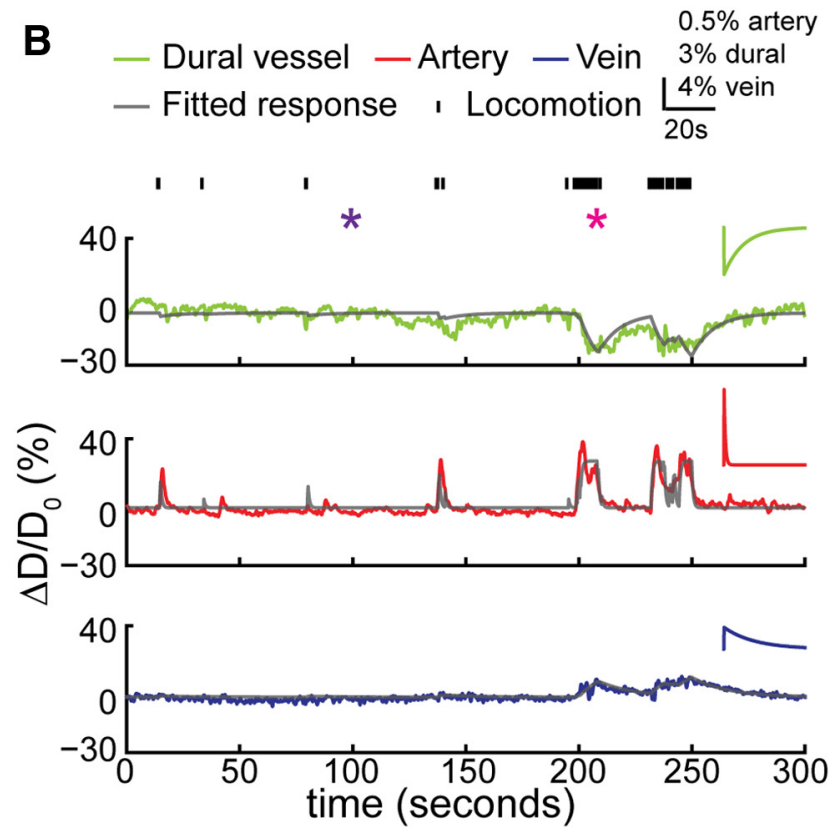

C
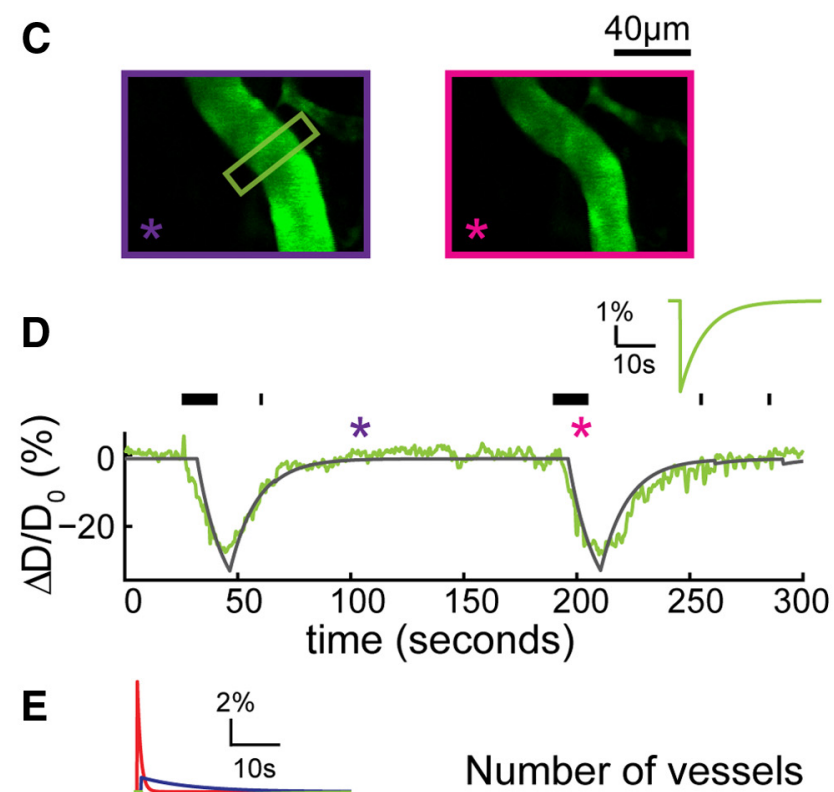

Number of vessels

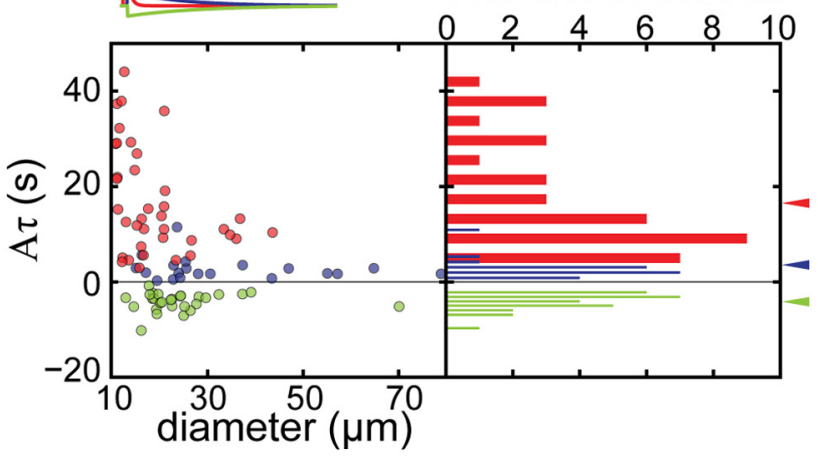

change and the locomotion. This model fit the dynamics of all three vessel types well [Pearson's correlation coefficient (cc), cc = $0.62 \pm 0.15$ for 54 arteries; $c c=0.66 \pm 0.11$ for 44 veins; $c c=$ $0.55 \pm 0.17$ for 68 dural vessels, from 21 mice]. The dilation amplitude parameter $(A)$ for arteries and veins were positive, indicating that locomotion was accompanied by the dilation of pial arteries and veins. The amplitude of the kernel fits of arteries, $A_{a}(7.48 \pm 12.86)$ was greater than that in veins, $A_{v}(0.15 \pm 0.12$ $p=0.006$, paired $t$ test). The amplitudes of dural vessel fits $\left(A_{d}\right)$ were all negative $(-0.93 \pm 2.42$, significantly smaller than $0, p=$ $5.10 \times 10^{-8}$, one-sided $t$ test), indicating a robust dural vessel constriction during locomotion. The veins had the largest time constants $\left(\tau_{v}=24.9 \pm 15.4 \mathrm{~s}\right)$, followed by dural vessels $\left(\tau_{d}=\right.$ $24.4 \pm 31.4 \mathrm{~s})$, whereas arteries $\left(\tau_{a}=3.3 \pm 20.4 \mathrm{~s}\right)$ had substantially faster dynamics than the other two vessel types. The total dilation integrated over time in response to a single brief running impulse, $A \tau$ (Fig. $2 D)$, was significantly larger in arteries $\left(A_{a} \tau_{a}=\right.$ $6.9 \pm 5.4 \mathrm{~s})$ than in veins $\left(A_{v} \tau_{v}=3.7 \pm 3.5 \mathrm{~s} ; p=0.04\right.$, paired $t$ test), whereas $A \tau$ in dural vessels was negative $\left(A_{d} \tau_{d}=-3.8 \pm\right.$ $2.6 \mathrm{~s}$, significantly smaller than $0, p=6.26 \times 10^{-16}$, one-sided $t$ test). The relationship between dural vessel diameter and $A \tau$ was weak $\left(A \tau=-0.09 \times\right.$ diameter $\left.-2.03, R^{2}=0.02\right)$. We also found that dural vessels $\left(t_{d}=2.7 \pm 4.4 \mathrm{~s}\right.$, significantly greater than 0 , $p=9.90 \times 10^{-6}$, one sided $t$ test $)$ and pial veins $\left(t_{d}=1.9 \pm 1.8 \mathrm{~s}\right.$, significantly greater than $0, p=3.43 \times 10^{-4}$, one-sided $t$ test) had delayed responses to locomotion, whereas pial arteries responded with a very short latency $\left(t_{d}=0.07 \pm 0.17 \mathrm{~s}\right)$.

These data show that dural vessels over the somatosensory cortex, in contrast to pial arteries and veins, constricted in response to locomotion and with an appreciable delay. The relatively large time constants of the dural vessel constrictions indicate that they will only constrict substantially in response to sustained locomotion or stimulation events, similar to the dilation dynamics of pial veins in response to sensory stimulation and locomotion (Drew et al., 2011; Gao et al., 2015; Huo et al., 2015a). The good agreement between the changes in vessel diameter and the linear convolution model shows that constriction of dural vessels was coupled tightly to behavior. In a series of pilot experiments, we attempted to test whether prolonged vibrissae

$\leftarrow$

Figure 3. Dural vessels in the visual cortex also constricted during locomotion. A, 2PLSM images of the vasculature in the visual cortex during periods of quiescence (left, enclosed by purple box) and locomotion (right, enclosed by magenta box). Green, red, and blue boxes denote the location where the dural vessel, pial artery, and vein diameters were measured. $\boldsymbol{B}$, Time courses of diameter changes of the measured three vessels in $\boldsymbol{A}$ (top, dural vessel; middle, pial artery; bottom, pial vein). Tick marks on the top denote locomotion events. Purple and magenta asterisks indicate the time points of quiescence and locomotion images in $\boldsymbol{A}$, respectively. Gray lines show the fitted response for each of the three vessels (correlation coefficient of dural vessel, $c c=0.63$; artery, $c c=0.56$; vein, $c c=0.59)$. Insets are the impulse responses by model fitting of the three vessels, respectively. C, 2PLSM images of a second example dural vessel over the visual cortex. Left, Image taken when the animal was stationary. Right, Image taken when the animal was locomoting. D. Time course of diameter changes (green line) of the measured dural vessel in C. Black tick marks denote locomotion events. Purple and magenta asterisks indicate the time points of the frames used in $\boldsymbol{C}$. The gray line shows the fitted response $\left(A,-0.50 ; \tau, 12.11 \mathrm{~s} ; t_{d}, 5.31 \mathrm{~s}, c c=0.87\right)$. Inset shows the impulse response by model fitting of the dural vessel. $\boldsymbol{E}$, Summary of the values of the fitted impulse response integrated area $(A \tau)$ of the impulse response of all the imaged vessels in the visual cortex ( $n=7$ mice). Green, red, and blue arrowheads indicate the mean $A \tau$ for dural vessels, pial arteries, and pial veins, respectively. The integrated dilation was larger in arteries $(16.72 \pm 11.11 \mathrm{~s})$ than in veins $\left(2.71 \pm 2.44 \mathrm{~s}, p=8.72 \times 10^{-7}\right.$, paired $t$ test $)$, and integrated dural vessel response was significantly negative $(-4.13 \pm 1.89 \mathrm{~s}$, significantly smaller than $\left.0, p=1.83 \times 10^{-14}\right)$. Inset shows the averaged impulse responses of each vessel type. 
stimulation would elicit dural vessel constriction. However, prolonged vibrissae stimulation would invariably cause the animals to locomote, so we did not pursue this approach further.

\section{Voluntary locomotion drove dural vessel constriction in the visual cortex}

We then asked whether locomotion-induced changes in dural vessel diameters were specific to the somatosensory cortex or whether dural vessels in the visual cortex also constricted during locomotion. As in the somatosensory cortex, dural vessels in the visual cortex constricted during locomotion, whereas pial arteries and veins dilated with similar amplitudes and dynamics as in the somatosensory cortex (Fig. 3). Given that previous studies have observed that locomotion in the dark drives substantial increases in neural activity in the visual cortex (Keller et al., 2012) and our 2PLSM imaging was done in darkness, it is likely that locomotion-linked increases in neural activity in the visual cortex drove pial vessels dilation.

To compare vessel dynamics across these two sensory regions, vessels in the visual cortex were fitted using the linear convolution model (Fig. 3). Responses of vessels in the visual cortex to locomotion were all well fitted by the model ( $c c=0.56 \pm 0.17$ for 37 arteries, $c c=0.59 \pm 0.17$ for 20 veins, $c c=0.63 \pm 0.14$ for 28 dural vessels, from 7 mice), not significantly different from those in the somatosensory cortex (artery, $p=0.11$; vein, $p=0.09$; dural vessel, $p=0.07$, paired $t$ test). There was no significant difference of fitted parameters of dural vessels between the two cortices $\left(A_{d}=-1.42 \pm 3.92, p=0.48 ; \tau_{d}=17.78 \pm 14.45 \mathrm{~s}, p=\right.$ 0.29 , paired $t$ test). However, the arteries in the visual cortex had a significantly larger fitted amplitude ( $43.97 \pm 41.40, p=5.60 \times$ $10^{-6}$, paired $t$ test $)$ and smaller time constants $(0.85 \pm 1.66 \mathrm{~s}, p=$ $4.94 \times 10^{-4}$, paired $t$ test) than the pial arteries in the somatosensory cortex, indicating that pial arteries in the visual cortex responded with faster dynamics to locomotion than those in the somatosensory cortex. Similarly, the pial veins in the visual cortex $\left(A_{v}=1.86 \pm 4.77, p=0.04 ; \tau_{v}=13.19 \pm 16.84 \mathrm{~s}, p=0.02\right)$ also responded with dynamics faster than those in the somatosensory cortex. The integrated dilation in response to a single impulse $(\mathrm{A} \tau)$ in pial arteries was much larger in the visual cortex (16.72 \pm $11.12 \mathrm{~s})$ than that in the somatosensory cortex $(6.9 \pm 5.4 \mathrm{~s}, p=$ $1.52 \times 10^{-5}$, paired $t$ test).

The constriction of dural vessels we observed cannot be attributed to a motion artifact or drift of the focus plane relative to dural vessels for several reasons. First, the dural vessel constriction was long lasting, persisting long after the locomotion event and after the artery diameters typically returned to baseline (Figs. 2, 3). Second, the onset of constriction was delayed substantially relative to locomotion onset (typically $>2 \mathrm{~s}$ ), whereas motion artifacts should occur synchronously with locomotion events. Last, pial vessels near the constricting dural vessels remained in the focus plane during constrictions (Figs. $2 B, 3 A, C$ ), indicating that there was no change in focal plane. These data showed that locomotion drives dilation of pial arteries and veins and constriction of dural vessels in both the somatosensory and visual cortices.

\section{Classification of dural vessels based on dynamics and anatomy}

Pial arterioles and venules can be identified clearly during imaging based on their morphology and connectivity patterns, because normally there are no arteriovenous anastomoses in the adult (Murphy et al., 2012). However, the vasculature of the dura is not as clearly demarcated into arteries and veins as in the cortex during in vivo imaging. We then asked whether the dural vessels we imaged that showed constriction during voluntary locomotion could be classified as arteries or veins.

We first used the fit parameters characteristics to determine whether dural vessels could be separated clearly into arteries or veins. We plotted the three fitted parameters (absolute value of amplitude, time constant, and response delay) for each of the three vessel types (Fig. 4A). Pial arteries and veins were mostly distinct from each other, but there was some overlap. Dural vessels had more "venous" characteristics, with a majority overlap with pial veins, although some were closer in characteristics to pial arteries, and some had responses that did not fall into either category. These results suggest that, although dural vessels tended to have more venous-like dynamics (larger time constants and longer delays), there was a continuum of dural vessel responses and some vessels that did not clearly fit in either category. This continuum of dural vessel dynamics makes a demarcation of individual dural vessels into arteries and veins based on dynamics alone difficult.

We then asked whether we could anatomically distinguish arteries and veins in the dura. Although cerebral veins have some contractile cells (Hartmann et al., 2015), imbuing them with some contractile abilities (Nilsson et al., 1997), arteries are surrounded by actin-rich smooth muscles that can be identified using phalloidin staining (Wulf et al., 1979), allowing arteries to be distinguished from veins histologically. We perfused the vasculature of mice with FITC-albumin to fill vessel lumens (Blinder et al., 2010, 2013) and then stained brains and mounted dura with phalloidin to visualize smooth muscles. With FITC-albumin perfusion and phalloidin staining, we were able to clearly distinguish pial arteries and veins in the brain (Fig. 4B). Arteries showed circumferential rings of smooth muscle labeled by phalloidin, whereas there was no circumferential actin labeling around veins, although longitudinal fibers were present. Using a whole-mount preparation, we were able to visualize arteries, capillaries, and veins in the dura (Fig. 4C-E). The vasculature of the dura mater was primarily composed of arteries, which formed a network of parallel vessels (Fig. 4C; Castelli and Huelke, 1965; Kerber and Newton, 1973; Fricke et al., 2001). Dural veins were less common than dural arteries but were present (Fig. 4D). There were also capillaries in the dura (Fig. $4 D$, right, light gray arrow), distinguishable by their small size and lack of smooth muscle. Although the dynamics of the measured dural vessels were more similar to pial veins, anatomically, the majority of the dural vessels present in the dural were arteries, most likely from the branches of middle and posterior meningeal arteries (Castelli and Huelke, 1965). These results suggest that the population of dural vessels that we observed constricting during locomotion were composed of both arterioles and venules. The contractile property of dural vessels during voluntary locomotion could be attributable to active constriction of smooth muscles on dural arteries (which would lead to decreased pressure in dural veins to cause their constriction) or a passive result of increased ICP during locomotion.

\section{ICP changes attributable to locomotion had faster dynamics than dural vessel constrictions}

We then asked whether the constriction of dural vessels during locomotion could be a passive process caused by the compression of dural vessels by increased ICP. Dilation of arteries and veins during locomotion will increase the cerebral blood volume, and, consequently, the ICP should rise (Krieger et al., 2012). Additionally, postural changes, such as those associated with movement, can cause dramatic increases in ICP (Qvarlander et al., 2013). If the dural ves- 


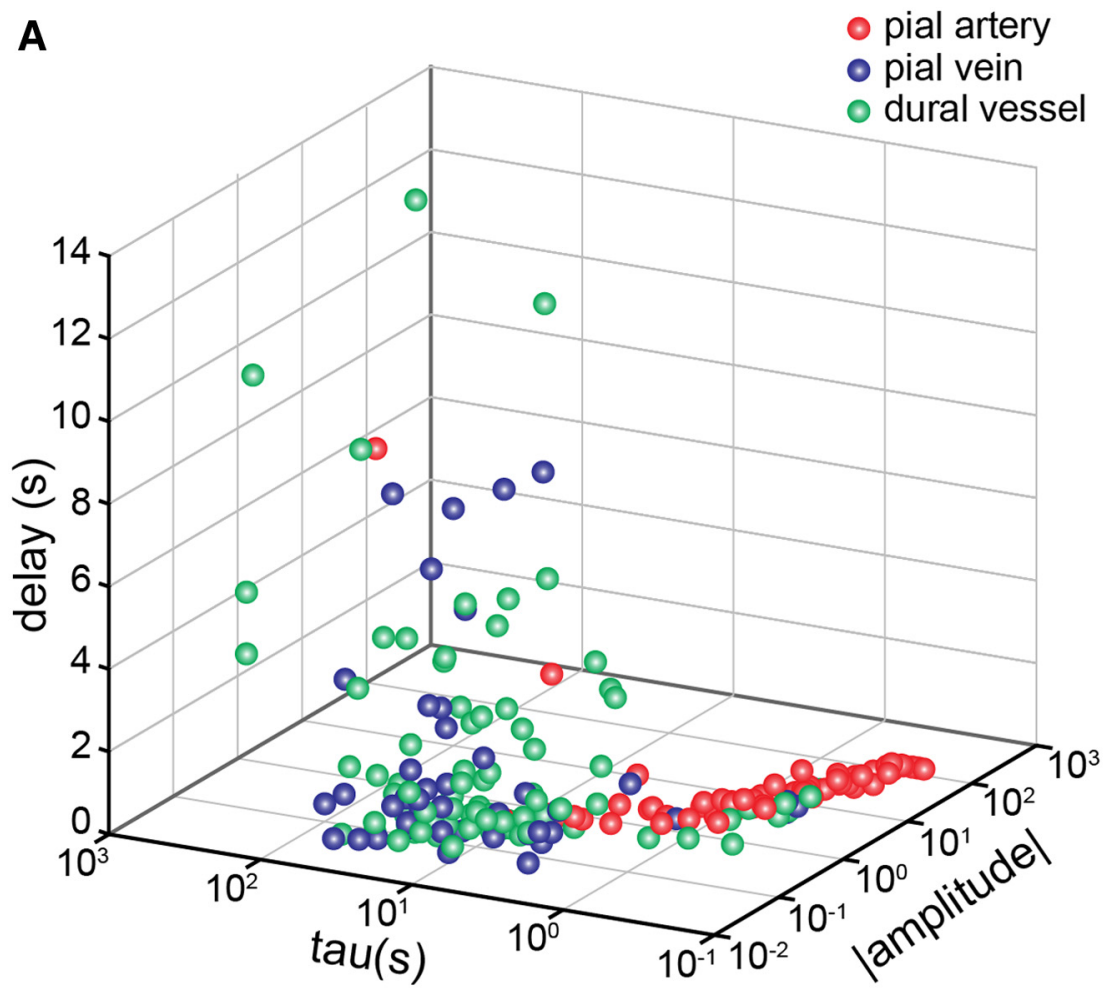

B

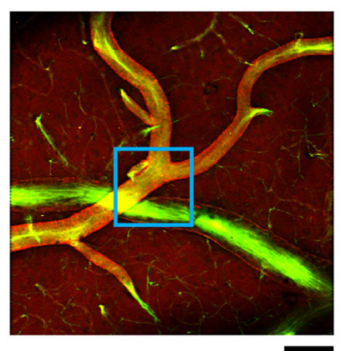

$100 \overline{\mu m}$

D
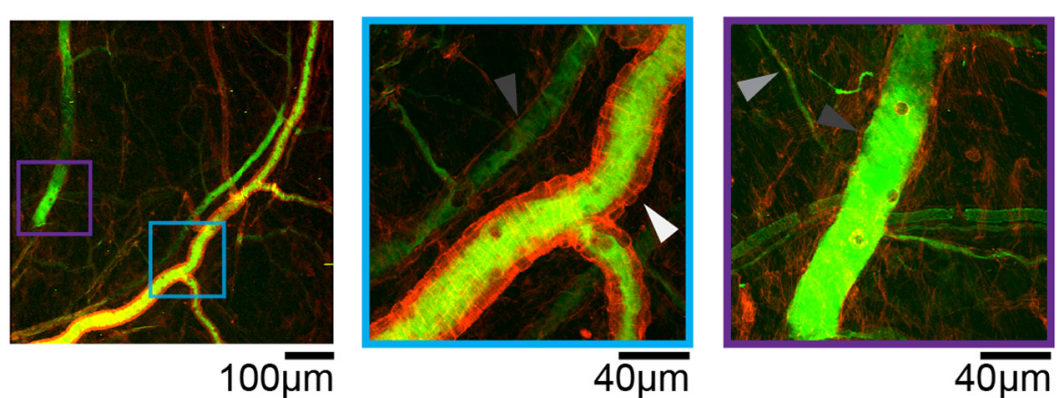

Figure 4. Segregation of dural vessel by fit parameters and anatomy. $\boldsymbol{A}$, Distribution of the fitted parameters (absolute value of $A, \tau$, and $t_{d}$ ) of pial arteries (red), pial veins (blue), and dural vessels (green) from the somatosensory and visual cortices. Pial arteries had larger $A$ and smaller $\tau$ compared with pial veins. Dural vessels were more "venous" in their fit parameters but overlapped with both groups. B, Phalloidin staining (red) of pial vessels perfused with FITC (green) imaged by 2PLSM. Left, 0ne pial artery and one pial vein. Light blue box encloses the zoomed in region on the right. Right, Zoomed-in image in the light blue box on the left showing that the smooth muscles on pial arteries (white arrow) were labeled by phalloidin. Lacking smooth muscles pial veins (dark gray arrow) were filled with FITC without phalloidin labeling. C, Epifluorescent image of the dura mater stained with phalloidin. Sagittal sinus is on the left. Smooth muscle cells around arteries were labeled strongly by phalloidin. Arteries in the dura ran parallel to each other and were much more common than veins. D, Dural vessels perfused with FITC ( $g r e e n$ ) and stained by phalloidin (red). Left, Image showing both arteries and veins of the dural vasculature. The light blue box and purple box enclose the magnified regions shown in the middle and right. Middle, Magnified region marked in light blue box on the left, with one dural artery and one dural vein. Similar to pial arteries, dural arteries (white arrow) were ensheathed by smooth muscles. Dural veins lacked smooth muscles (dark gray arrow). Right, Magnified region enclosed by the purple box on the left. Dark gray arrow marks the dural vein. Light gray arrow denotes a capillary. sels were compressed by increases in ICP, then the dynamics of their constriction during locomotion should closely mirror the changes in ICP. To test this hypothesis, we measured ICP during voluntary locomotion. Resting ICP was similar to previous measurements of ICP (Oshio et al., 2005; Hawthorne and Piper, 2014; Hiploylee and Colbourne, 2014; Fig. 5A,E). During locomotion, we observed substantial increases in ICP that onset quickly and then returned rapidly to baseline at the cessation of locomotion (Fig. $5 A, B$ ). We used the linear convolution model to quantify locomotioninduced ICP changes (Fig. 5C) so they could be compared with dural vessel constriction dynamics. Locomotion-induced ICP increases were well fitted with the linear convolution model ( $c c=0.53 \pm 0.11,8$ mice $)$. However, rather than a delayed response to locomotion, as was seen in dural vessels, ICP increased slightly before the locomotion event (Fig. $5 B ; t_{d}=-0.35 \pm 0.35 \mathrm{~s}$, significantly smaller than $0, p=0.006$, one-sided $t$ test). Increases in ICP before locomotion onset were likely caused by the shift in posture and body position before movement. The time constant of decay of ICP $\left(\tau_{p}=\right.$ $1.26 \pm 0.45 \mathrm{~s}$ ) was also much smaller than that of dural vessels in the somatosensory cortex $(p=0.002)$ and visual cortex $(p=$ $1.06 \times 10^{-6}$, paired $t$ test; Fig. $5 C$ ). The time constant of the ICP response was approximately half that of the cerebral arteries (Fig. 2). This is expected, because the change in arterial volume comprises the overwhelming majority of volume change in the vasculature to stimuli of a few seconds duration (Silva et al., 2007; Kim and Kim, 2010; Drew et al., 2011). If the dynamics of the arterial dilation can be fit with an exponential kernel, we would expect the ICP dynamics to follow similar exponential dynamics but have a time constant that is half as long. This is because the blood volume will follow the square of the diameter of the vessel (which will have an effective time constant half of that fitting of the diameter change), and ICP will, within the normal physiological range, be affected by the volume of arterial blood. These ICP measurements showed the dynamics of dural vessels during locomotion in both the somatosensory and visual cortices were substantially slower than ICP changes. We then tested whether increasing the ICP with the vasodilator isoflurane (Todd and Drummond, 1984; Fig. 5D,E), which directly acts on the smooth muscles (Flynn et al., 1992) to maximally dilate blood vessels, would compress the dural vessels. We did not use $\mathrm{CO}_{2}$, because vasodilatory levels of $\mathrm{CO}_{2}$ induce anxiety in mice (Taugher et al., 2014). Under isoflurane, 
A $\quad-$ ICP — Fitted response , Locomotion

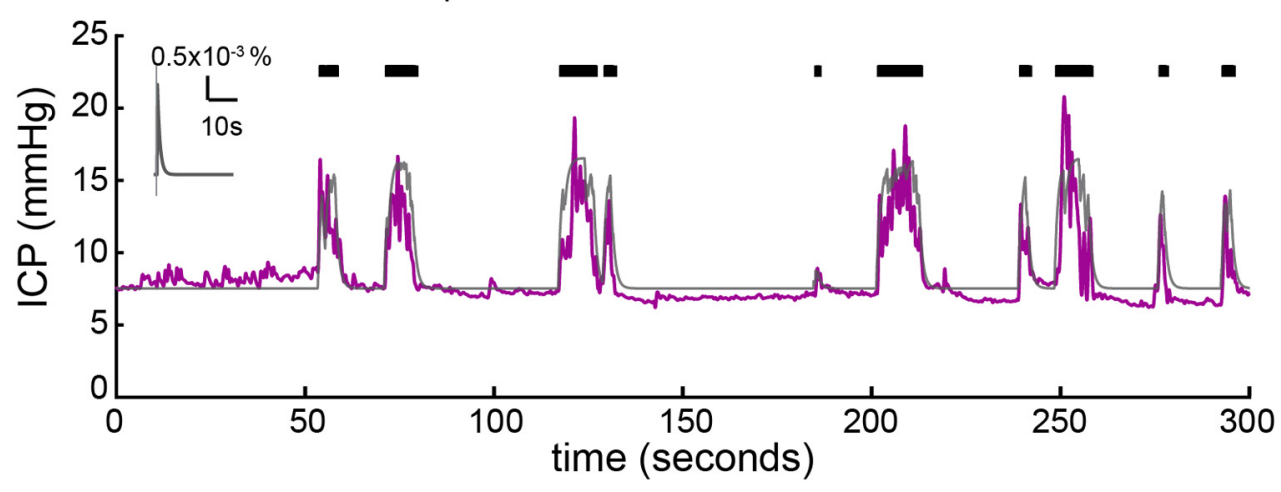

B
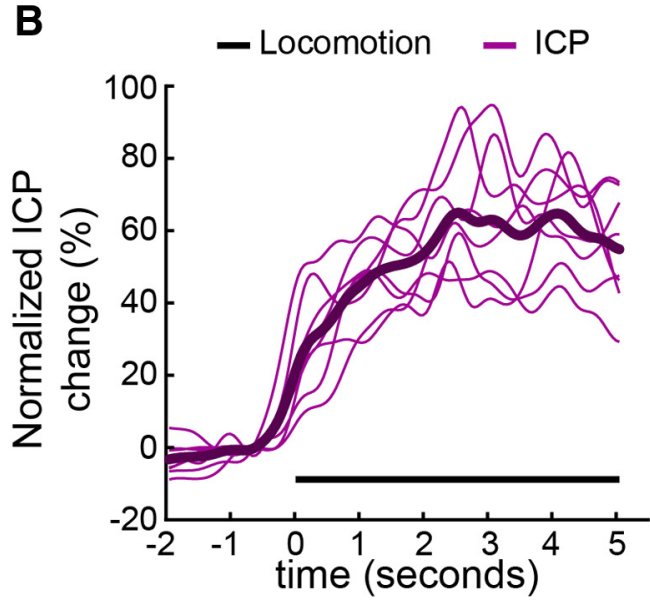

C

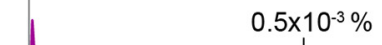

D

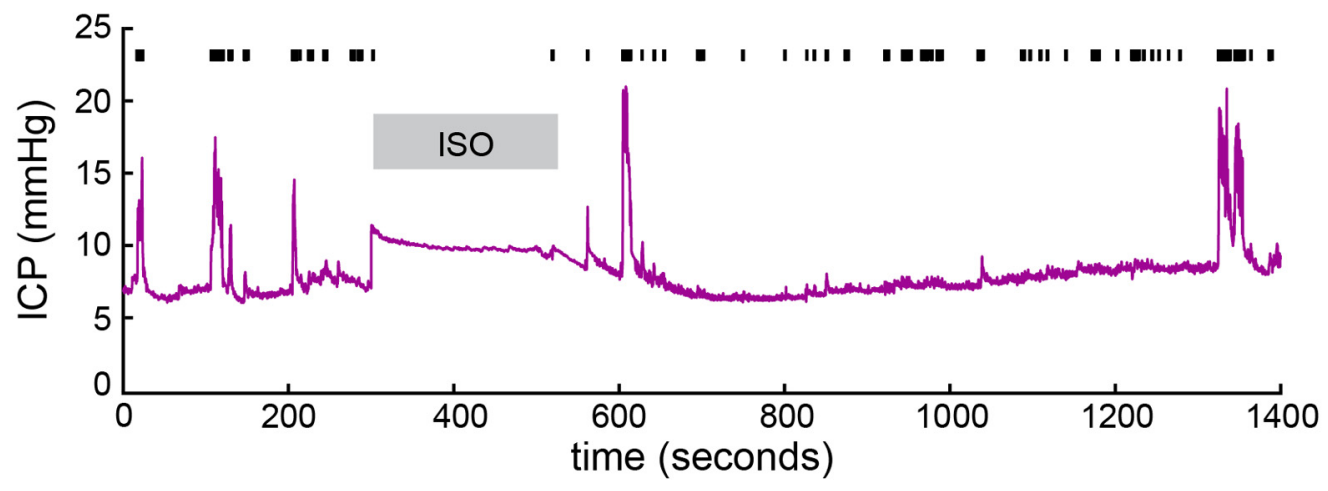

E

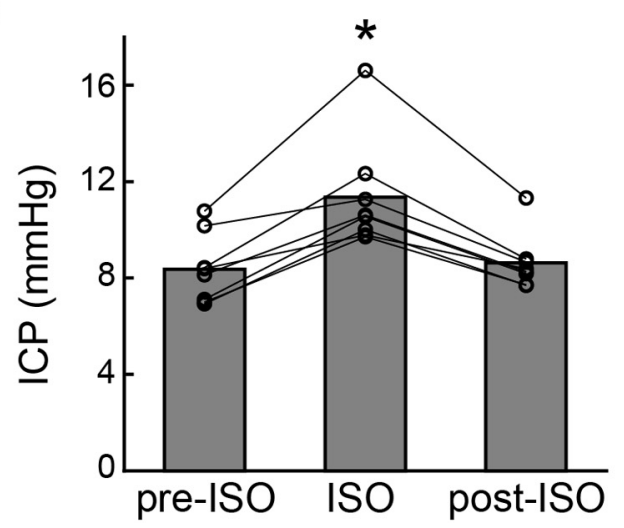

F

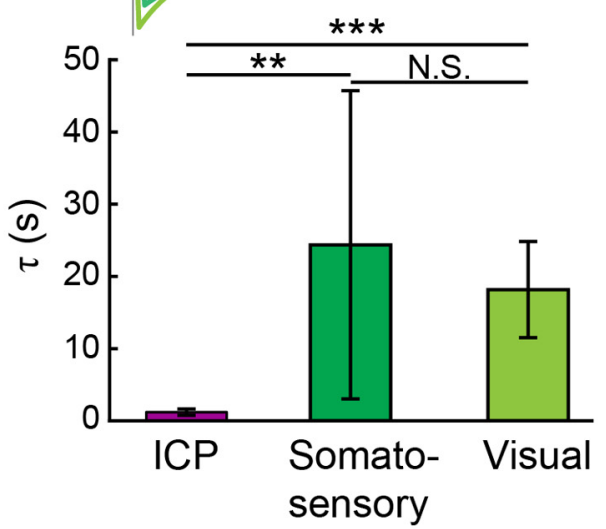


ICP was increased by $36.2 \pm 15.6 \%$ (Fig. $5 E$ ), consistent with pressure increases reported in previous studies (Todd and Drummond, 1984), and dural vessels were dilated $13.3 \pm 15.6 \%$ (Fig. 5F). The disassociation of ICP increase from dural vessel diameter under isoflurane and the mismatch in the temporal dynamics of ICP and dural vessels during locomotion indicate that dural vessel diameter was not slaved passively to ICP but is likely under active control.

\section{The headache-inducing peptide CGRP dilated dural, but not pial, vessels and dural vessel dilation was blocked by sumatriptan}

CGRP is an endogenous vasodilator, with intravenous injections of CGRP inducing immediate headaches that can be blocked by sumatriptan in humans (Petersen et al., 2005; Asghar et al., 2010, 2012). We first asked whether CGRP injection in mice caused behavioral changes that could reflect headache. If CGRP causes a decrease in spontaneous locomotion, this would support the hypothesis that dural vessel dilation is associated with a painful, headache-like state in mice (Kaiser et al., 2012). After a baseline period of imaging, the mouse was retro-orbitally injected with CGRP, sumatriptan, or CGRP plus sumatriptan, to mimic intravenous injections in human studies (Lassen et al., 2002; Asghar et al., 2010). Drugs changed significantly locomotion amount (unbalanced one-way ANOVA on log-transformed locomotion ratios, $\left.F_{(3,47)}=3.95, p=0.014\right)$. Post hoc Tukey's test showed that CGRP significantly decreased locomotion 10-15 min after injection compared with the saline control group (post hoc multiple comparison, Tukey's test, $p=0.013$; Fig. $6 D)$. Sumatriptan blocked the CGRP-induced decrease in locomotion (post hoc multiple comparison, Tukey's test, $p=$ 0.0031). We also observed that CGRP injections induced diarrhea in the injected mice, similar to the gastrointestinal problems associated with headaches reported in humans (Aamodt et al., 2008). The dilation of dural vessels were associated

\section{$\leftarrow$}

Figure 5. Dural vessel constriction during locomotion was not a passive process caused by ICP increases. $A$, An example of ICP dynamics during voluntary locomotion in one animal. Magenta trace shows the ICP changes, and gray line is the linear convolution model fit. Black tick marks are locomotion events. ICP decreases very rapidly during locomotion. Inset shows the impulse response of ICP. $\boldsymbol{B}$, Averaged ICP percentage changes in response to 5 s locomotion. The thin lines are the data from individual animals, and the thick line is the average across all the animals. Note that ICP rises before the onset of locomotion. C, The fitted time constant of ICP impulse response $(1.26 \pm 0.45 \mathrm{~s}, 8$ mice) was significantly smaller than the time constant of the dural vessel impulse response in the somatosensory cortex (dark green, $24.38 \pm 21.34 \mathrm{~s}$, averaged across 21 mice; $p=0.002$, paired $t$ test) and visual cortex (light green, $18.17 \pm 6.67 \mathrm{~s}$, averaged across 7 mice; $p=1.06 \times 10^{-6}$, paired $t$ test). ${ }^{*} 0.01<p<0.05$, ${ }^{* *} 0.001<p<$ $\left.0.01,{ }^{* * *} p<0.001\right)$. Inset shows the averaged impulse responses of ICP and dural vessels in the somatosensory and visual cortices. The gray line indicates the initiation of locomotion. The ICP impulse response is shown on a different scale from the vessel diameter change. $\boldsymbol{D}$, An example of ICP recording before, during, and after isoflurane treatment. Isoflurane increases ICP immediately, and ICP recovers to baseline $\sim 2 \mathrm{~min}$ after isoflurane removal, consistent with the time course of isoflurane-induced arterial dilation (Shirey et al., 2015). Black tick marks are locomotion events. $\boldsymbol{E}$, The averaged ICP before (pre-ISO, 8.36 $\pm 1.44 \mathrm{mmHg}$ ), during (ISO, $11.45 \pm$ $2.29 \mathrm{mmHg}$ ), and after (post-ISO, $8.62 \pm 1.16 \mathrm{mmHg}$ ) isoflurane treatment. Isoflurane treatment significantly changes ICP ( $p=0.0027, F_{(1,21)}=7.94$, unbalanced one-way ANOVA). Isoflurane increased ICP significantly relative to ICP before ( $p=0.0048$, post hoc multicomparison Tukey's test) and after ( $p=0.0091$, post hoc multi-comparison Tukey's test) isoflurane treatment. $\boldsymbol{F}$, Under isoflurane, the vessel diameter ratio (after/before isoflurane treatment) was vessel type dependent $\left(p=3.28 \times 10^{-4}, F_{(1,67)}=9.06\right.$, unbalanced oneway ANOVA). Post hoc multi comparison Tukey's tests showed that arteries $(n=15,1.40 \pm$ $0.25)$ were significantly more dilated than veins $(n=26,1.13 \pm 0.16, p=0.0006)$ and dural vessels ( $n=29,1.14 \pm 0.22, p=0.001$ ). Dilations of dural vessels and veins were not significantly different $(p=0.95)$. All three vessels were significantly dilated by isoflurane (artery, $p=3.19 \times 10^{-5}$; vein, $p=5.12 \times 10^{-4}$; dural vessel, $p=0.002$, one-sided $t$ test). with behavioral changes, consistent the hypothesis that intravenous injection of CGRP induces a headache-like state in mice, just as it does in humans.

We then asked which, if any, intracranial vessels in the awake animal are affected by CGRP. Although it has been studied heavily, the locus or loci of vascular action of CGRP in the awake animal is still not clear (Williamson et al., 1997a; Schoonman et al., 2008; Asghar et al., 2010, 2011; Gupta et al., 2010). Voluntary locomotion drove the constriction of dural vessels, distinct from the dynamics of pial vessels, suggesting that the two sets of vessels do not respond uniformly. To determine whether CGRP has different vascular effects on dural and pial vessels and whether CGRP can change dural vessel responses during behavior, we quantified the changes in diameter of pial and dural vessels in response to CGRP and/or sumatriptan. The vessel diameter was significantly affected by the interaction between vessel type and drug treatment (unbalanced two-way ANOVA, $F_{(6,96)}=4.57$, $p=0.0004)$. CGRP caused dramatic dilations in dural vessels $10-15$ min after injection (Fig. $6 A, B$; postdrug/predrug injection diameter ratio was significantly greater than saline control, post hoc multiple comparison, Tukey's test, $p=0.0008$ ). The timeline of the vasodilatory effects of CGRP was consistent with the short half-life $(\sim 7 \mathrm{~min})$ of CGRP in the bloodstream (Bhatt et al., 2014). However, CGRP did not significantly affect the diameters of pial arteries or veins compared with saline injections (Fig. $6 A, B$; pial artery, $p=0.9999$; pial vein, $p=0.9965$, post hoc multiple comparison, Tukey's test). Thus, intravenous injection of CGRP dilated dural vessels but not pial vessels. This result is consistent with other studies using closed cranial window in anesthetized rats that CGRP topical perfusion only induce dural vasodilation but not pial vessels (Williamson et al., 1997a; Gupta et al., 2010). Dural vessel dilations were blocked by coinjection of sumatriptan, a 5-HT receptor agonist (Peroutka, 1990; Fig. 6A, B; dural vessel post-CGRP/pre-CGRP injection diameter ratio > dual vessel post-CGRP + sumatriptan/pre-CGRP + sumatriptan injection diameter ratio, post hoc multiple comparison, Tukey's test, $p=7.5 \times 10^{-5}$ ) but had no effect on pial arteries and veins (post/pre diameter ratios compared with saline control, post hoc multiple comparison, Tukey's test: artery, $p=1.0$; vein, $p=1.0$ ). Administration of sumatriptan alone caused small decreases of dural vessel diameter, but these decreases were not significant (diameter ratios compared with saline control, post hoc multiple comparison, Tukey's test: pial artery, $p=1.0$; pial vein, $p=1.0$; dural vessel, $p=0.9806)$. In humans, administration of sumatriptan alone causes constriction of dural vessels (Humphrey and Feniuk, 1991; Jansen et al., 1992; Henkes et al., 1996; Amin et al., 2013b). The lack of significant vasoconstriction by sumatriptan in our study could be attributable to dose differences, because the effects of sumatriptan on plasma extravasation and vessel diameter are dose dependent (Jansen-Olesen et al., 2013). This difference could also be attributable to species differences (Shepherd et al., 1997) or the different vessel sizes studied. These data suggested that, in awake animal, intravenous CGRP injection dilated only dural vessels, not pial vessels, and sumatriptan could block this dilation but did not merely work through a vasoconstrictory effect.

\section{Interactions between CGRP and locomotion on dural vessel diameters}

We then applied the linear convolution model to data obtained after CGRP injection to determine whether the dynamics or amplitudes of the locomotion-induced constrictions of dural vessels were altered by CGRP administration. After CGRP injections, we observed 
A

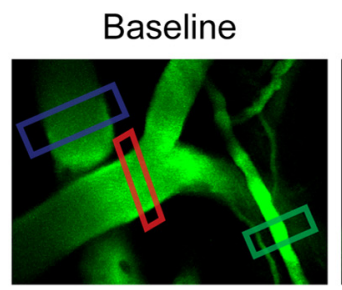

B

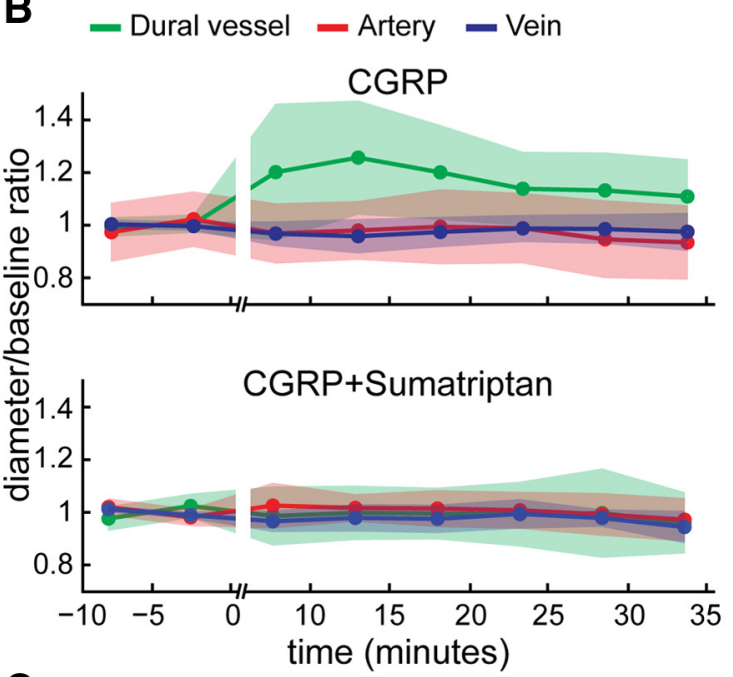

C
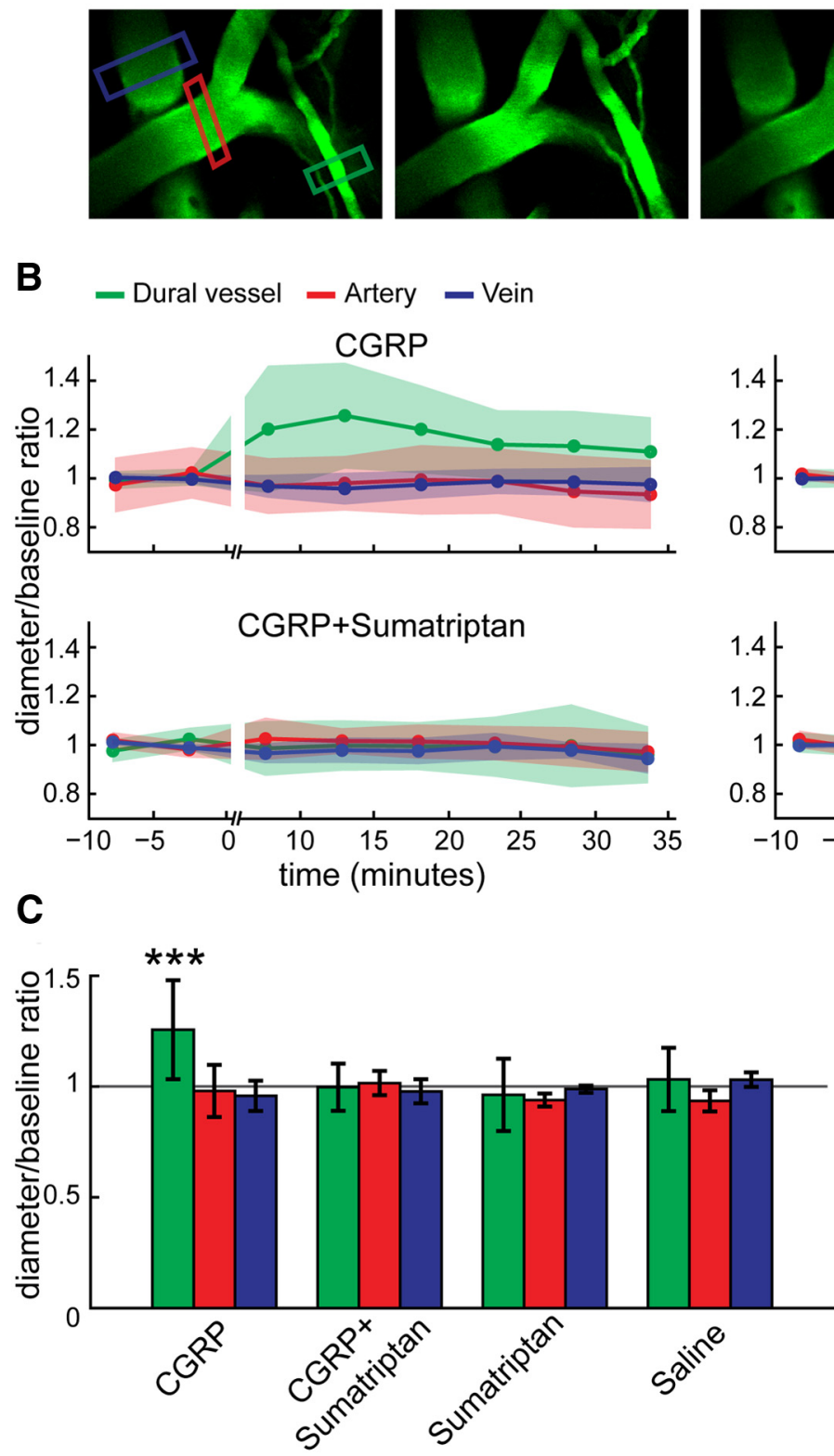

Sumatriptan
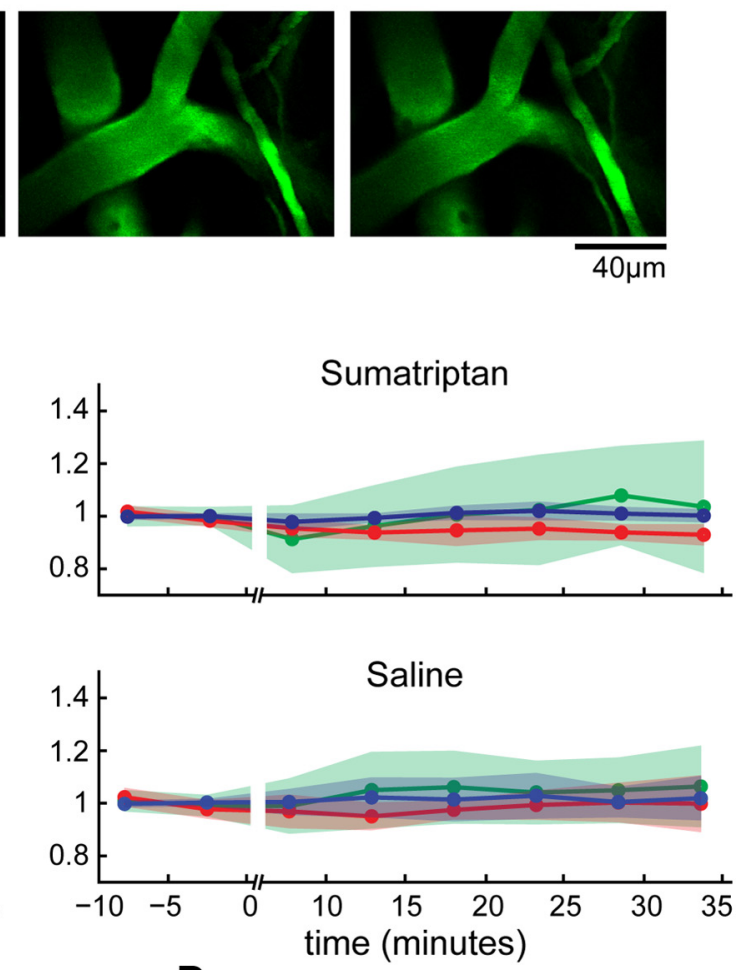

D

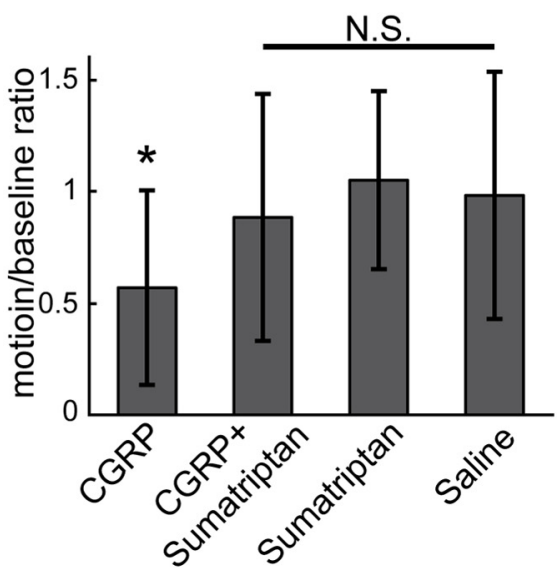

Figure 6. CGRP injection dilated dural vessels and decreased voluntary locomotion. A, 2PLSM images of the same region after different drug treatments. Each drug treatment was done on a different day, and images were taken from periods when the mouse was still. Green, red, and blue boxes enclose the measured dural vessel, pial artery, and pial vein, respectively. Dural vessels, but not pial arteries or veins, were dilated substantially after GGRP injection. Sumatriptan blocked the CGRP-induced dilation. $\boldsymbol{B}$, Vessel diameter changes before and after drug treatments across the time. Vessel diameter was normalized to the preinjection baseline diameter, and only still periods were used. Shaded areas denote SDs. C, Vessel diameter ratio (after drug treatment/baseline) $10-15$ min after drug treatments. Only the diameter ratio of dural vessel under CGRP treatment was significantly larger than the saline control group and all other drug combination groups $(* * * p<$ 0.001, two-way ANOVA and multi-comparison Tukey's test). Data consisted of 46 dural vessels, 33 arteries, and 24 veins from 11 mice. $\boldsymbol{D}$, Ratio of mouse locomotion before and $10-15$ min after drug injection (11 mice). Only CGRP treatment decreased locomotion relative to saline ( ${ }^{*} p=0.013$, multi-comparison Tukey's test).

that the dural vessels still constricted during locomotion, and these constrictions could still be fit by the convolution model $\left(\mathrm{CC}_{d \text {-GCRP }}\right.$ $=0.53 \pm 0.11, \mathrm{CC}_{d \text {-saline }}=0.49 \pm 0.05, p=0.39$, paired $t$ test $)$. The absolute amplitudes of these constrictions did not significantly change $\left(A_{d \text {-GCRP }}=-1.33 \pm 2.58 ; A_{d \text {-saline }}=-0.44 \pm 0.37, p=0.38\right.$, paired $t$ test). The amount of time locomoting was reduced dramatically after CGRP injection (Fig. 6D), accounting for the increased variability in the amplitude of locomotion-induced constriction under CGRP. Similarly, we did not find major changes in the dynamics of pial vessels after CGRP injections compared with saline injections $\left(A \tau_{a \text {-CGRP }}=17.4 \pm 19.6 \mathrm{~s}, A \tau_{a \text {-saline }}=9.3 \pm 7.2 \mathrm{~s}, p=0.23, A \tau_{v \text {-CGRP }}\right.$ $=3.3 \pm 3.2 \mathrm{~s}, A \tau_{v \text {-saline }}=2.5 \pm 1.2 \mathrm{~s}, p=0.45$, paired $t$ test).
Locomotion-induced constrictions of dural vessels were not large enough to return the dural vessel diameter to their pre-CGRP injection baseline during normal locomotion bouts, particularly as locomotion was reduced (Fig. 7). To determine whether sustained locomotion would constrict the dural vessels below baseline, we simulated the constriction produced by a 30-s-long, sustained locomotion bout using our linear model. A $30 \mathrm{~s}$ locomotion bout is at the very extreme end of locomotion durations for head-fixed mice under our experimental conditions (Huo et al., 2015a). We found that, with 30-s-long locomotion bouts, the vessels would constrict to $5.04 \pm 28.71 \%$ above the pre-CGRP injection baseline diameter, indicating that regular pattern of locomotion would still set the dural 


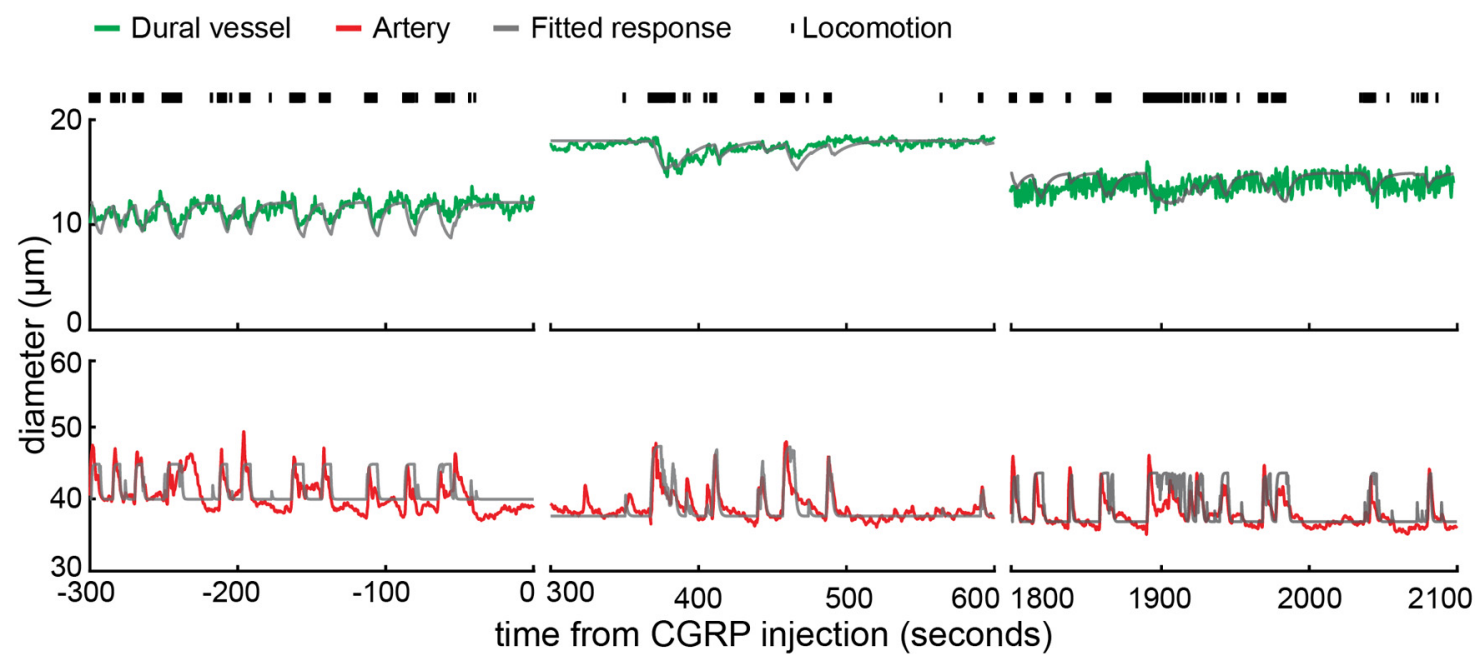

Figure 7. Interaction of locomotion-driven vascular dynamics with CGRP. Example showing the effects of locomotion on a dural vessel (green, top) and a pial artery (red, bottom) from the somatosensory cortex during voluntary locomotion (same vessels as in Fig. 6A). Respective linear model fits are shown as gray lines. (GRP dramatically increased the dural vessel baseline diameter $5 \mathrm{~min}$ after the injection (top middle), and the diameter returned back to baseline $30 \mathrm{~min}$ later (top right). The dural vessel constricted during locomotion both before and after (GRP treatment, although the locomotion-driven constriction was not large enough to return the dural vessels diameter to their pre-CGRP baseline. The pial artery baseline diameter and dynamics during voluntary locomotion were not affected by CGRP injection (note different diameter scale from dural vessel).

vessel tone above its normal resting baseline. If we simulated a complete saturating locomotion bout of $500 \mathrm{~s}$, we would expect a constriction by $-5.07 \pm 30.52 \%$ of their pre-CGRP baseline tone. These data suggest that normal locomotion behavior is insufficient to constrict dural vessels to the resting levels after CGRP injection, and the animals would have to be locomoting constantly, which greatly increases ICP, to constrict their dural vessels to their resting pre-CGRP baseline.

\section{Discussion}

We imaged the dynamics of dural vessels in awake mice in response to normal physiological and pathological stimuli. We found that dural vessels constricted during voluntary locomotion (Figs. 2, 3). This dural vessel constriction was related linearly to locomotion and delayed relative to the start of locomotion, pial vessel dilation, and ICP increases (Figs. 2, 3). Although CGRP dilated dural vessels and decreased spontaneous locomotion (Fig. 6), it did not block the constriction of dural vessels during voluntary locomotion or affect the responses of pial vessels to locomotion (Fig. 7). Both the vascular and behavioral effects of CGRP were blocked by sumatriptan. Our results point to a model in which resting dural vessel tone in the awake brain is set by a balance of vasoconstrictory and vasodilatory input, consistent with previous work showing stimulation of nerves innervating the dura drives constriction and dilation of dural vessels (Williamson et al., 1997a; Li et al., 2009).

In human studies, intravenous CGRP injection reliably causes headache within 45 min of injection (Asghar et al., 2010, 2012; Hansen et al., 2010; Amin et al., 2013a), but the vascular changes associated with these headaches, if any, were controversial. Our results showed that only dural vessels, but not pial vessels, were dilated immediately by CGRP injection. The lack of response from pial vessels in our awake mice is consistent with results showing that pial vessels do not respond to intracarotid or topical administration of CGRP (Gupta et al., 2010) and the ability of sumatriptan, which cannot cross the blood-brain barrier (Tfelt-Hansen, 2010), to prevent CGRP-induced headaches. It is important to note that the smooth muscles surrounding the surface pial arteries of the brain are outside the blood-brain barrier and exposed to the same CSF as the smooth muscle around the dural vessels. If CGRP can leave dural vessels and enter into the CSF in which it can cause relaxation of dural vessels, it should also have similar effects on cerebral arteries if they were responsive to CGRP, because CGRP innervation of vessels is on the outermost adventitial layer of the vessel (Nakakita, 1990). Although we chose the dose $\left(10^{-3} \mathrm{mg} / \mathrm{kg}\right)$ and method of delivery (intravenous injection) of CGRP to mimic human studies (Lassen et al., 2002), other animals studies have used intracerebroventricular or intraparenchymal injections of CGRP (Williamson et al., 1997a; Gupta et al., 2010; Kaiser et al., 2012). Although some of these animal studies report dilation of pial vessels and behavioral effects, their results are hard to compare with the human intravenous infusion experiments because CGRP receptors are present on central neurons (Oliver et al., 1998; Han et al., 2005). Any behavioral change or vessel dilation elicited by injection of CGRP into the brain is likely a result of the change in neural activity, rather than the perception of pain or direct vasodilatory action. Neural activity was not recorded in these experiments, making the interpretation of the results problematic. Because the intraparenchymal/ventricular delivery and mechanism of action is so different from that in human studies and likely causes unknown changes in neural activity, these studies are not likely to be good models of human pathology.

There are several caveats to our work. First, although we observed that CGRP reduces voluntary locomotion, we have no real way of determining whether CGRP produces a headache-like pain in a mouse model. This is a common limitation with all animal pain studies, in which one must make inferences about pain perception from behaviors. It is possible that the decrease in locomotion we observe after CGRP injection could be attributable to a nonspecific effect other than headache. However, it is unlikely that a CGRPinduced decrease in blood pressure underlies the decrease in locomotion, because previous experiments from our laboratory indicate that altering blood pressure pharmacologically, either up or down, does not change the amount of spontaneous locomotion in headfixed mice (Huo et al., 2015b). Second, though our polished thinskull window preparation does not alter ICP or cause detectable inflammation (Drew et al., 2010), it could still alter the sensitivity of the meningeal nerves or damage the nerves innervating the dura (Kosaras et al., 2009). However, our experimental preparation is less 
invasive than previous experiments on anesthetized animals that involved the removal of skull (Williamson et al., 1997b), and our experiments were done several days to weeks after the surgery, which presumably would allow the animals to recover from acute effects of surgery. Dural vessels may respond differentially to different subtypes of CGRP, although previous studies did not find differences in the response of cranial vessels to different subtypes of CGRP (Jansen-Olesen et al., 2003; Petersen et al., 2004). The vessels we measured in mice with 2PLSM are distinct in both their size and position from those measured in human studies. The dural vessels we imaged were small vessels on the dorsal aspect of the cortex, whereas human imaging experiments usually focus on the large meningeal arteries, which are located near the cranial base. Both the size of a vessel and its location may determine its responsiveness. Smaller cortical arterioles are more reactive (dilate more) in response to hypercapnia (Lee et al., 2001) and sensory stimulation (Drew et al., 2011; Gao et al., 2015; Huo et al., 2015a). Cerebral arteries that perfuse different territories can also have heterogeneous responses to the same vasodilator or vasoconstrictor (Hamel et al., 1988), and similar location dependence of responses may apply to dural arterioles. The size- and position-dependent reactivity of arterioles could be the cause of differences between our measurements in mice and those made in humans (Amin et al., 2013b). Last, intravenous injection of CGRP likely only captures a subset of the normal pathological causes of headaches.

Our most surprising observation was that voluntary locomotion drove a long-lasting constriction of dural vessels during normal and pathological states. Why might dural vessels constrict during locomotion? One possibility could be that dural vessels are constricting to accommodate the increased volume of arteries and veins associated with locomotion (Gao et al., 2015; Huo et al., 2015a). The "space-conserving" effects of dural vessel constriction would probably not have a significant influence on ICP for several reasons. First, the time course of dural vessel constriction was much slower than increases in ICP (Fig. 5), because the ICP would return to baseline before some dural vessels even began to constrict, attributable to their delayed response, minimizing the effect of dural vessel constriction in moderating locomotion-induced increases in ICP. Additionally, there are relatively few dural vessels compared with cortical vessels (Bruner et al., 2011), so changes in the diameter of dural vessels will likely have a minimal effect on ICP. The constriction of dural vessels might be a myogenic response to increased blood pressure (Davis and Hill, 1999), because the blood pressure in the dural vessels could rise with the increased heart rate during locomotion (Huo et al., 2015b). The constriction could be attributable to the action of peripheral nerves, because vasoconstrictory sympathetic outflow should increase, and vasodilatory parasympathetic outflow should withdraw during locomotion (Edvinsson and Uddman, 1981; Christensen and Galbo, 1983; Tuor, 1990). It could be that the constriction of dural vessels serves to shunt blood to other regions (such as the skin and/or brain) that require increased blood flow during locomotion. Last, one very speculative hypothesis is that the tone of dural vessels regulates the mechanosensitivity of the dural nerves. The highly innervated dura is ideally positioned to serve as an ICP sensor. The sensitivity of these nerves would be increased by dural vessel dilation, potentially through some mechanical action, such as stretching or compression, of the dural vessels on the nearby nerves, although vessel dilation in and of itself may not drive mechanosensory neurons. Natural behaviors, such as locomotion (Fig. 5), coughing (Williams, 1976), and sleep (Cooper and Hulme, 1966), all are accompanied by substantial (up to twofold) increases in ICP. Increases in ICP this large are also associated with pathology (Hiploylee and Colbourne, 2014), meaning that the animal would need some way of differentiating between pathological and normal, selfgenerated ICP increases. The animal would want to decrease its sensitivity to these non-pathological, self-generated ICP increases. This pressure-sensor dura hypothesis could also account for the pain accompanying migraines, in which the brain might swell as a result of spreading depression (Lauritzen et al., 2011). Increased sensitivity of the dural nerves could outlast the initial noxious stimulus, which could account for the temporal mismatch between vasodilators and the onset of severe head pain (Amin et al., 2012). Although the idea that dilation or constriction of dural blood vessels might influence the sensitivity of the nerves innervating the dura is highly speculative, there is evidence that vascular tone affects the responses of nearby mechanosensory fibers in the gut (Brunsden et al., 2007; Humenick et al., 2015). A more complete evaluation of this hypothesis will require a better understanding of the neuroanatomy and physiology linking dural mechanosensitivity to ICP and ICP regulation.

\section{References}

Aamodt AH, Stovner LJ, Hagen K, Zwart JA (2008) Comorbidity of headache and gastrointestinal complaints. The Head-HUNT Study. Cephalalgia 28:144-151. CrossRef Medline

Amin FM, Asghar MS, Guo S, Hougaard A, Hansen AE, Schytz HW, van der Geest RJ, de Koning PJ, Larsson HB, Olesen J, Ashina M (2012) Headache and prolonged dilatation of the middle meningeal artery by PACAP38 in healthy volunteers. Cephalalgia 32:140-149. CrossRef Medline

Amin FM, Asghar MS, Hougaard A, Hansen AE, Larsen VA, de Koning PJ, Larsson HB, Olesen J, Ashina M (2013a) Magnetic resonance angiography of intracranial and extracranial arteries in patients with spontaneous migraine without aura: a cross-sectional study. Lancet Neurol 12:454-461. CrossRef Medline

Amin FM, Asghar MS, Ravneberg JW, de Koning PJ, Larsson HB, Olesen J, Ashina M (2013b) The effect of sumatriptan on cephalic arteries: A 3T MR-angiography study in healthy volunteers. Cephalalgia 33:1009-1016. CrossRef Medline

Asghar MS, Hansen AE, Kapijimpanga T, van der Geest RJ, van der Koning P, Larsson HB, Olesen J, Ashina M (2010) Dilation by CGRP of middle meningeal artery and reversal by sumatriptan in normal volunteers. Neurology 75:1520-1526. CrossRef Medline

Asghar MS, Hansen AE, Amin FM, van der Geest RJ, Koning PV, Larsson HB, Olesen J, Ashina M (2011) Evidence for a vascular factor in migraine. Ann Neurol 69:635-645. CrossRef Medline

Asghar MS, Hansen AE, Larsson HB, Olesen J, Ashina M (2012) Effect of CGRP and sumatriptan on the BOLD response in visual cortex. J Headache Pain 13:159-166. CrossRef Medline

Balo J (1950) The dural venous sinuses. Anat Rec 106:319-325. CrossRef Medline

Berwick J, Martin C, Martindale J, Jones M, Johnston D, Zheng Y, Redgrave P, Mayhew J (2002) Hemodynamic response in the unanesthetized rat: intrinsic optical imaging and spectroscopy of the barrel cortex. J Cereb Blood Flow Metab 22:670-679. CrossRef Medline

Bhatt DK, Gupta S, Olesen J, Jansen-Olesen I (2014) PACAP-38 infusion causes sustained vasodilation of the middle meningeal artery in the rat: possible involvement of mast cells. Cephalalgia 34:877-886. CrossRef Medline

Blinder P, Shih AY, Rafie C, Kleinfeld D (2010) Topological basis for the robust distribution of blood to rodent neocortex. Proc Natl Acad Sci U S A 107:12670-12675. CrossRef Medline

Blinder P, Tsai PS, Kaufhold JP, Knutsen PM, Suhl H, Kleinfeld D (2013) The cortical angiome: an interconnected vascular network with noncolumnar patterns of blood flow. Nat Neurosci 16:889-897. CrossRef Medline

Boynton GM, Engel SA, Glover GH, Heeger DJ (1996) Linear systems analysis of functional magnetic resonance imaging in human V1. J Neurosci 16:4207-4221. Medline

Brennan KC, Charles A (2010) An update on the blood vessel in migraine. Curr Opin Neurol 23:266-274. CrossRef Medline

Bruner E, Mantini S, Musso F, De La Cuétara JM, Ripani M, Sherkat S (2011) The evolution of the meningeal vascular system in the human genus: from brain shape to thermoregulation. Am J Hum Biol 23:35-43. CrossRef Medline

Brunsden AM, Brookes SJ, Bardhan KD, Grundy D (2007) Mechanisms underlying mechanosensitivity of mesenteric afferent fibers to vascular flow. Am J Physiol Gastrointest Liver Physiol 293:G422-G428. CrossRef Medline 
Castelli WA, Huelke DF (1965) The arterial supply of the dura mater of the Rhesus monkey. Anat Rec 152:155-160. CrossRef Medline

Chen Q, Cichon J, Wang W, Qiu L, Lee SJ, Campbell NR, Destefino N, Goard MJ, Fu Z, Yasuda R, Looger LL, Arenkiel BR, Gan WB, Feng G (2012) Imaging neural activity using Thyl-GCaMP transgenic mice. Neuron 76: 297-308. CrossRef Medline

Christensen NJ, Galbo H (1983) Sympathetic nervous activity during exercise. Annu Rev Physiol 45:139-153. CrossRef Medline

Cooper R, Hulme A (1966) Intracranial pressure and related phenomena during sleep. J Neurol 29:564-570.

Davis MJ, Hill MA (1999) Signaling Mechanisms Underlying the Vascular Myogenic Response. Physiol Rev 79:387-423. Medline

Dombeck DA, Harvey CD, Tian L, Looger LL, Tank DW (2010) Functional imaging of hippocampal place cells at cellular resolution during virtual navigation. Nat Neurosci 13:1433-1440. CrossRef Medline

Drew PJ, Shih AY, Driscoll JD, Knutsen PM, Blinder P, Davalos D, Akassoglou K, Tsai PS, Kleinfeld D (2010) Chronic optical access through a polished and reinforced thinned skull. Nat Methods 7:981-984. CrossRef Medline

Drew PJ, Shih AY, Kleinfeld D (2011) Fluctuating and sensory-induced vasodynamics in rodent cortex extend arteriole capacity. Proc Natl Acad Sci U S A 108:8473-8478. CrossRef Medline

Du W, Stern JE, Filosa JA (2015) Neuronal-derived nitric oxide and somatodendritically released vasopressin regulate neurovascular coupling in the rat hypothalamic supraoptic nucleus. J Neurosci 35:5330-5341. CrossRef Medline

Edvinsson L, Uddman R (1981) Adrenergic, cholinergic and peptidergic nerve fibres in dura mater-involvement in headache? Cephalalgia 1:175-179. CrossRef Medline

Flynn NM, Buljubasic N, Bosnjak ZJ, Kampine JP (1992) Isoflurane produces endothelium-independent relaxation in canine middle cerebral arteries. Anesthesiology 76:461-467. CrossRef Medline

Franklin KB, Paxinos G (1997) Mouse brain in stereotaxic coordinates. San Diego: Academic.

Fricke B, Andres KH, Von Düring M (2001) Nerve fibers innervating the cranial and spinal meninges: morphology of nerve fiber terminals and their structural integration. Microsc Res Tech 53:96-105. CrossRef Medline

Gao YR, Drew PJ (2014) Determination of vessel cross-sectional area by thresholding in Radon space. J Cereb Blood Flow Metab 34:1180-1187. CrossRef Medline

Gao YR, Greene SE, Drew PJ (2015) Mechanical restriction of intracortical vessel dilation by brain tissue sculpts the hemodynamic response. Neuroimage 115:162-176. CrossRef Medline

Gehrmann J, Hammer PE, Maguire CT, Wakimoto H, Triedman JK, Berul CI (2000) Phenotypic screening for heart rate variability in the mouse. Am J Physiol Heart Circ Physiol 279:H733-H740. Medline

Gupta S, Bhatt DK, Boni LJ, Olesen J (2010) Improvement of the closed cranial window model in rats by intracarotid infusion of signalling molecules implicated in migraine. Cephalalgia 30:27-36. CrossRef Medline

Hamel E, Edvinsson L, MacKenzie ET (1988) Heterogeneous vasomotor responses of anatomically distinct feline cerebral arteries. Br J Pharmacol 94:423-436. CrossRef Medline

Han JS, Li W, Neugebauer V (2005) Critical role of calcitonin gene-related peptide 1 receptors in the amygdala in synaptic plasticity and pain behavior. J Neurosci 25:10717-10728. CrossRef Medline

Hansen JM, Hauge AW, Olesen J, Ashina M (2010) Calcitonin gene-related peptide triggers migraine-like attacks in patients with migraine with aura. Cephalalgia 30:1179-1186. CrossRef Medline

Hartmann DA, Underly RG, Grant RI, Watson AN, Lindner V, Shih AY (2015) Pericyte structure and distribution in the cerebral cortex revealed by high-resolution imaging of transgenic mice. Neurophotonics 2:041402. CrossRef Medline

Hawthorne C, Piper I (2014) Monitoring of intracranial pressure in patients with traumatic brain injury. Front Neurol 5:121. CrossRef Medline

Henkes H, May A, Kühne D, Berg-Dammer E, Diener HC (1996) Sumatriptan: vasoactive effect on human dural vessels, demonstrated by subselective angiography. Cephalalgia 16:224-230. CrossRef Medline

Hiploylee C, Colbourne F (2014) Intracranial pressure measured in freely moving rats for days after intracerebral hemorrhage. Exp Neurol 255: 49-55. CrossRef Medline

Hirano Y, Stefanovic B, Silva AC (2011) Spatiotemporal evolution of the functional magnetic resonance imaging response to ultrashort stimuli. J Neurosci 31:1440-1447. CrossRef Medline
Humenick A, Chen BN, Wiklendt L, Spencer NJ, Zagorodnyuk VP, Dinning PG, Costa M, Brookes SJ (2015) Activation of intestinal spinal afferent endings by changes in intra-mesenteric arterial pressure. J Physiology 593:3693-3709. CrossRef

Humphrey PP, Feniuk W (1991) Mode of action of the anti-migraine drug sumatriptan. Trends Pharmacol Sci 12:444-446. CrossRef Medline

Huo BX, Smith JB, Drew PJ (2014) Neurovascular coupling and decoupling in the cortex during voluntary locomotion. J Neurosci 34:10975-10981. CrossRef Medline

Huo BX, Gao YR, Drew PJ (2015a) Quantitative separation of arterial and venous cerebral blood volume increases during voluntary locomotion. Neuroimage 105:369-379. CrossRef Medline

Huo BX, Greene SE, Drew PJ (2015b) Venous cerebral blood volume increase during voluntary locomotion reflects cardiovascular changes. Neuroimage 118:301-312. CrossRef Medline

Jansen I, Edvinsson L, Mortensen A, Olesen J (1992) Sumatriptan is a potent vasoconstrictor of human dural arteries via a 5-HT1-like receptor. Cephalalgia 12:202-205. CrossRef Medline

Jansen-Olesen I, Jørgensen L, Engel U, Edvinsson L (2003) In-depth characterization of CGRP receptors in human intracranial arteries. Eur J Pharmacol 481:207-216. CrossRef Medline

Jansen-Olesen I, Tfelt-Hansen P, Olesen J (2013) Animal migraine models for drug development: status and future perspectives. CNS Drugs 27: 1049-1068. CrossRef Medline

Kaiser EA, Kuburas A, Recober A, Russo AF (2012) Modulation of CGRPinduced light aversion in wild-type mice by a 5-HT(1B/D) agonist. J Neurosci 32:15439-15449. CrossRef Medline

Keller GB, Bonhoeffer T, Hübener M (2012) Sensorimotor mismatch signals in primary visual cortex of the behaving mouse. Neuron 74:809-815. CrossRef Medline

Kerber CW, Newton TH (1973) The macro and microvasculature of the dura mater. Neuroradiology 6:175-179. CrossRef Medline

Kim SG, Ogawa S (2012) Biophysical and physiological origins of blood oxygenation level-dependent fMRI signals. J Cereb Blood Flow Metab 32:1188-1206. CrossRef Medline

Kim T, Kim SG (2010) Temporal dynamics and spatial specificity of arterial and venous blood volume changes during visual stimulation: implication for BOLD quantification. J Cereb Blood Flow Metab 31:1211-1222. CrossRef Medline

Komiyama T, Sato TR, O'Connor DH, Zhang Y-X, Huber D, Hooks BM, Gabitto M, Svoboda K (2010) Learning-related fine-scale specificity imaged in motor cortex circuits of behaving mice. Nature 464:1182-1186. CrossRef Medline

Kosaras B, Jakubowski M, Kainz V, Burstein R (2009) Sensory innervation of the calvarial bones of the mouse. J Comp Neurol 515:331-348. CrossRef Medline

Krieger SN, Streicher MN, Trampel R, Turner R (2012) Cerebral blood volume changes during brain activation. J Cereb Blood Flow Metab 32:16181631. CrossRef Medline

Lassen LH, Haderslev PA, Jacobsen VB, Iversen HK, Sperling B, Olesen J (2002) CGRP may play a causative role in migraine. Cephalalgia 22: 54-61. CrossRef Medline

Lauritzen M, Dreier JP, Fabricius M, Hartings JA, Graf R, Strong AJ (2011) Clinical relevance of cortical spreading depression in neurological disorders: migraine, malignant stroke, subarachnoid and intracranial hemorrhage, and traumatic brain injury. J Cereb Blood Flow Metab 31:17-35. CrossRef Medline

Lee SP, Duong TQ, Yang G, Iadecola C, Kim SG (2001) Relative changes of cerebral arterial and venous blood volumes during increased cerebral blood flow: implications for BOLD fMRI. Magnet Reson Med 45: 791-800. CrossRef

Li N, Jia X, Murari K, Parlapalli R, Rege A, Thakor NV (2009) High spatiotemporal resolution imaging of the neurovascular response to electrical stimulation of rat peripheral trigeminal nerve as revealed by in vivo temporal laser speckle contrast. J Neurosci Methods 176:230-236. CrossRef Medline

Martins C, Yasuda A, Campero A, Ulm AJ, Tanriover N, Rhoton AJ (2005) Microsurgical anatomy of the dural arteries. Neurosurgery 56:211-251; discussion 211-251. Medline

Masamoto K, Kanno I (2012) Anesthesia and the quantitative evaluation of neurovascular coupling. J Cereb Blood Flow Metab 32:1233-1247. CrossRef Medline

Murphy PA, Kim TN, Lu G, Bollen AW, Schaffer CB, Wang RA (2012) 
Notch4 normalization reduces blood vessel size in arteriovenous malformations. Sci Transl Med 4:117ra8. CrossRef Medline

Nakakita K (1990) Peptidergic innervation in the cerebral blood vessels of the guinea pig: an immunohistochemical study. J Cereb Blood Flow Metab 10:819-826. CrossRef Medline

Nilsson T, Cantera L, Adner M, Edvinsson L (1997) Presence of contractile endothelin-A and dilatory endothelin-B receptors in human cerebral arteries. Neurosurgery 40:346-351; discussion 351-353. CrossRef Medline

Nizar K, Uhlirova H, Tian P, Saisan PA, Cheng Q, Reznichenko L, Weldy KL, Steed TC, Sridhar VB, MacDonald CL, Cui J, Gratiy SL, Sakadzić S, Boas DA, Beka TI, Einevoll GT, Chen J, Masliah E, Dale AM, Silva GA, Devor A (2013) In vivo stimulus-induced vasodilation occurs without IP3 receptor activation and may precede astrocytic calcium increase. J Neurosci 33:8411-8422. CrossRef Medline

O'Connor DH, Peron SP, Huber D, Svoboda K (2010) Neural activity in barrel cortex underlying vibrissa-based object localization in mice. Neuron 67:1048-1061. CrossRef Medline

Oliver KR, Wainwright A, Heavens RP, Hill RG, Sirinathsinghji DJ (1998) Distribution of novel CGRP1 receptor and adrenomedullin receptor mRNAs in the rat central nervous system. Brain Res Mol Brain Res 57: 149-154. CrossRef Medline

Oshio K, Watanabe H, Song Y, Verkman AS, Manley GT (2005) Reduced cerebrospinal fluid production and intracranial pressure in mice lacking choroid plexus water channel Aquaporin-1. FASEB J 19:76-78. CrossRef Medline

Peroutka SJ (1990) Sumatriptan in acute migraine: pharmacology and review of world experience. Headache 30 [Suppl] 2:554-560.

Petersen KA, Birk S, Doods H, Edvinsson L, Olesen J (2004) Inhibitory effect of BIBN4096BS on cephalic vasodilatation induced by CGRP or transcranial electrical stimulation in the rat. Br J Pharmacol 143:697-704. CrossRef Medline

Petersen KA, Birk S, Lassen LH, Kruuse C, Jonassen O, Lesko L, Olesen J (2005) The CGRP-antagonist, BIBN4096BS does not affect cerebral or systemic haemodynamics in healthy volunteers. Cephalalgia 25:139-147. CrossRef Medline

Pietrobon D, Moskowitz MA (2013) Pathophysiology of migraine. Annu Rev Physiol 75:365-391. CrossRef Medline

Qvarlander S, Sundström N, Malm J, Eklund A (2013) Postural effects on intracranial pressure: modeling and clinical evaluation. J Appl Physiol 115:1474-1480. CrossRef Medline

Rice FL, Bourgeois JR, Xie JY, Kopruzinski CM, Eyde N, Popreca F, Albrecht PJ (2015) Dural sensory innervation expresses unique opioid and adrenergic receptor subtypes: implications for migraine pathology and treatment. Soc Neurosci Abstr 41:56.20.

Schoonman GG, van der Grond J, Kortmann C, van der Geest RJ, Terwindt GM, Ferrari MD (2008) Migraine headache is not associated with cerebral or meningeal vasodilatation-a 3T magnetic resonance angiography study. Brain 131:2192-2200. CrossRef Medline

Shepherd SL, Williamson DJ, Beer MS, Hill RG, Hargreaves RJ (1997) Differential effects of 5-HT1B/1D receptor agonists on neurogenic dural plasma extravasation and vasodilation in anaesthetized rats. Neuropharmacology 36:525-533. CrossRef Medline

Shih AY, Mateo C, Drew PJ, Tsai PS, Kleinfeld D (2012) A polished and reinforced thinned-skull window for long-term imaging of the mouse brain. J Vis $\operatorname{Exp}(61) ;$ pii:3742. CrossRef

Shirey MJ, Smith JB, Kudlik DE, Huo B-X, Greene SE, Drew PJ (2015) Brief anesthesia, but not voluntary locomotion, significantly alters cortical temperature. J Neurophysiol 114:3009-3022. CrossRef

Silva AC, Koretsky AP, Duyn JH (2007) Functional MRI impulse response for BOLD and CBV contrast in rat somatosensory cortex. Magn Reson Med 57:1110-1118. CrossRef Medline

Sofroniew NJ, Cohen JD, Lee AK, Svoboda K (2014) Natural whiskerguided behavior by head-fixed mice in tactile virtual reality. J Neurosci 34:9537-9550. CrossRef Medline

Taugher RJ, Lu Y, Wang Y, Kreple CJ, Ghobbeh A, Fan R, Sowers LP, Wemmie JA (2014) The bed nucleus of the stria terminalis is critical for anxiety-related behavior evoked by $\mathrm{CO} 2$ and acidosis. J Neurosci 34: 10247-10255. CrossRef Medline

Tfelt-Hansen PC (2010) Does sumatriptan cross the blood-brain barrier in animals and man? J Headache Pain 11:5-12. CrossRef Medline

Tian P, Teng IC, May LD, Kurz R, Lu K, Scadeng M, Hillman EM, De Crespigny AJ, D’Arceuil HE, Mandeville JB, Marota JJ, Rosen BR, Liu TT, Boas DA, Buxton RB, Dale AM, Devor A (2010) Cortical depth-specific microvascular dilation underlies laminar differences in blood oxygenation level-dependent functional MRI signal. Proc Natl Acad Sci U S A 107:15246-15251. CrossRef Medline

Todd M, Drummond JC (1984) A comparison of the cerebrovascular and metabolic effects of halothane and isoflurane in the cat. Anesthesiology 60:276-282. CrossRef Medline

Tsai PS, Kaufhold JP, Blinder P, Friedman B, Drew PJ, Karten HJ, Lyden PD, Kleinfeld D (2009) Correlations of neuronal and microvascular densities in murine cortex revealed by direct counting and colocalization of nuclei and vessels. J Neurosci 29:14553-14570. CrossRef Medline

Tuor UI (1990) Local distribution of the effects of sympathetic stimulation on cerebral blood flow in the rat. Brain Res 529:224-231. CrossRef Medline

Vazquez AL, Noll DC (1998) Nonlinear aspects of the BOLD response in functional MRI. Neuroimage 7:108-118. CrossRef Medline

Wiig H, Reed RK (1983) Rat brain interstitial fluid pressure measured with micropipettes. Am J Physiol 244:H239-H246. Medline

Williams B (1976) Cerebrospinal fluid pressure changes in response to coughing. Brain 99:331-346. CrossRef Medline

Williamson DJ, Hargreaves RJ, Hill RG, Shepheard SL (1997a) Sumatriptan inhibits neurogenic vasodilation of dural blood vessels in the anaesthetized rat-intravital microscope studies. Cephalalgia 17:525-531. CrossRef Medline

Williamson DJ, Hargreaves RJ, Hill RG, Shepheard SL (1997b) Intravital microscope studies on the effects of neurokinin agonists and calcitonin gene-related peptide on dural vessel diameter in the anaesthetized rat. Cephalalgia 17:518-524. CrossRef Medline

Wolff HG (1948) Headache and other head pain. New York: Oxford UP.

Wood J, Garthwaite J (1994) Models of the diffusional spread of nitric oxide: implications for neural nitric oxide signalling and its pharmacological properties. Neuropharmacology 33:1235-1244. CrossRef Medline

Wulf E, Deboben A, Bautz FA, Faulstich H, Wieland T (1979) Fluorescent phallotoxin, a tool for the visualization of cellular actin. Proc Natl Acad Sci U S A 76:4498-4502. CrossRef Medline 